MILITARY TECHNICAL COLLEGE CAIRO - ESYPT

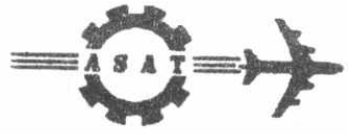

$7^{\text {th }}$ INTERNATIONAL CONF. ON AEROSPACE SCIENCES \& AVIATION TECHNOLOGY

\title{
Improving the Transient Response of the Turbocharged Diesel Engine
}

\author{
M.A.SHAHIN", G.A.HUSSEIN", M.A.FAYED “"
}

\begin{abstract}
The transient performance of the turbocharged vehicle diesel engine is inferior to the naturally aspirated engine of the same output. This problem tends to appear at high ratings, and becomes more serious as load increases. In this work, two techniques are applied separately and concurrently in order to improve the transient response of the turbocharged engine. In the first, compressed air is fed into the engine intake manifold for a short period in order to satisfy the suddenly increased demand on air supply. In the second method, fuel and air are injected inside a special comoustion chamber attached to the engine exhaust manifold. The combustion products are discharged into the manifold as close as possible to the turbine entry in order to increase the energy available to the exhaust turbine.
\end{abstract}

\section{KEYWORDS}

Turbocharging - Transient response - Diesel Engines

\section{INTRODUCTION}

During the last two decades, turbocharging has largely contributed in developing diesel engines with higher specific power output. Supercharging pressure has risen steadily, and thus some problems associated with turbocharging have become more significant [1]. Among these problems, is the inferior transient performance of the turbocharged compared to the naturally aspirated engine of the same output [2]. This poor transient response could be attributed to the different characteristics of the engine and the turbocharger; being displacement and rotary

\footnotetext{
- Associate Professor, Dpt. of Mech.?ower, Militeary Téchnical College * Graduate PhD. Student, Dot. of Mech.Power, Military Technical Colleg
} 
Proceedings of the $7^{\text {th }}$ ASAT Conf. $13-15$ May 1997

\begin{tabular}{|l|l|}
\hline $\mathrm{PR}-4$ & 460 \\
\hline
\end{tabular}

machines respectively. Only part of the energy utilized by the turbine is delivered to the compressor, the remainder is consumed in overcoming the inertia of the turbocharger and accelerating its rotating components. Thus, the supercharging pressure developed at increasing engine speed or load, is likely to be below that developed when operating steadily under the same instantaneous conditions [3]. The decreased boost pressure will result in deteriorated combustion, smoke emission, lower power output and consequently poor engine response.

Several techniques have been developed to improve the transient response of turbocharged diesel engines used in traction applications. These techniques may be classified into two main groups. Eirst, methods that improve the characteristics of the turbocharging system, such as matching, fuel controlling devices and variable geometry turbines and compressors $[4,5,6, \ldots]$. Secondly, those techniques that introduce additional energy in order to accelerate the turbocharger as the engine starts to accelerate $[7,8, \ldots]$.

In this work, two additional energy systems are presented, tested and assessed. These two systems were used separately and concurrently in order to improve the transient response of the turbocharged diesel engine.

\section{THE TEST FACILITY}

A complete engine test facility, furnished with an electronic data acquisition system, was erected and used. A four stroke 5.67 liters water cooled, direct injection turbocharged diesel engine, coupled to a Heenan type hydraulic dynamometer, form the basic test rig constituents. Instrumentation included devices for measuring engine and turbocharger speeds, dynamometer reading, fuel rack position, inlet air and exhaust gas temperatures, in addition to the pressure history inside the engine cylinder, high pressure filel line, exhaust pipes and inlet air manifold. The engine speed was measured using an electric tachometer. Turbocharger speed, on the other hand, was measured using a specially designed system based on photoelectric techniques. A strain gauge pressure transducer was employed for measuring the pressure inside the intake manifold. The angular position of the dynamometer pointer was converted to an electric signal using a rotary potentiometer and a conditioning circuit. The outputs of all measuring instruments were fed to the data acquisition system in order to record their variations with time during each test.

The two presented additional energy systems were designed, manufactured and mounted on the engine. Figure 1 shows a 
schematic of the test facility including these two systems. In the first, compressed air (at 7 bar) is fed into the intake manifold from an air tank via a manually controlled cock. The tank, which is large enough to keep the pressure constant while air is injected, is charged prior to the experiment using an air compressor. The air entrance to the intake manifold, is arranged so that air is injected in the same direction of the main air stream. The system is manually operated for a period of 2 seconds when the engine is suddenly accelerated or externally loaded. This period is just enough for approximately 5 liters of compressed air to be supplied in excess to the output of the turbocharger compressor.

In the second system, additional heat energy is supplied to the turbine by burning fuel into an external combustion chamber. A pintle type injector is used to spray the fuel inside the chamber. Ignition on the other hand, is triggered by an electric discharge using a spark plug with its associated electrical circuit. The air needed for combustion is fed from the engine general purpose compressed air system. An electric pump feeds fuel from the main fuel tank to the injector via an electromagnetic valve situated near the injector. This valve controls the fuel pressure during injection and at the same time works as an alternator switch for the ignition coil primary winding. The combustion chamber discharges into one exhaust pipe, just before the turbine entry, through a one way valve. The fuel pump control handle is provided with a switch that is simultaneously used to close the ignition coil circuit and actuate the electromagnetic fuel valve. The system is adjusted to insure the injection of $1.5 \mathrm{~cm}^{3}$ of fuel, with the appropriate amount of air, during a period of 5 seconds commencing from the moment at which the engine is suddenly accelerated or externally loaded.

\section{THE TEST PROGRAM}

Two groups of tests were carried out. In the first group, the engine transient response to acceleration demands was measured. During these tests, the dynamometer water flow rate was kept unchanged at preadjusted values. The engine was accelerated to the target speed by suddenly moving the fuel pump control lever to a new pre-estimated position.

Measurement of the engine response to sudden increase in dynamometer loads, was performed in the second group of tests. The fuel pump control lever was locked at its initial setting throughout each test of this group.

During each test, measured parameters were recorded at $0.1 \mathrm{sec}$. intervals for a period of approximately 25 seconds. For reasons of comparisons, each test was 
performed 4 times under the same transient requirements at different modes as follows:

Mode 1 : Free response of the turbocharged engine.

Mode 2 : Response of the turbocharged engine with air injected into the intake manifold.

Mode 3 : Response of the turbocharged engine with exhaust combustion using the turbine energy boosting device.

Mode 4 : Response of the turbochrged engine with air injection and exhaust combustion.

\section{RESULTS AND DISCUSSION}

\section{Acceleration Tests}

Figure (2) shows the measured data when the engine, normally aspirated, was accelerated from 1500 to $3200 \mathrm{rpm}$ with the initial dynamometer torque set to 110 N.m. The displayed results show that the engine reached its final speed in approximately 4 seconds, a period which was expected to increase with higher initial setting of the load torque. The experimental results of the four test modes under the same initial dynamometer setting are shown if Fig.(3). The turbocharger speed is seen to increase sharply during the engine acceleration period. After reaching a maximum value, the turbocharger speed drops to the final steady value as the fuel rack retreats with the consequent decrease in fueling. Variations of the intake manifold pressure are closely connected to the changes in the turbocharger speed. Therefore, the boost pressure rises sharply then decreases to its final steady value following the variations of the compressor speed. As the boost pressure increases, the fuel rack limiter control device is moved to allow more fueling (the aneroid effect). consequently, the brake torque during acceleration increases to a higher value.

Similar trends are observed when air is injected in the intake manifold. However, the plotted results show that tine engine accelerates to the final speed in almost 2.5 seconds (compared to nearly 4 seconds in the previous case). The apparent conclusion is that air injection technique can improve the engine acceleration ability by helping the compressor in quickly fulfilling the increased demand on air flow rate. This may remedy the disadvantageous effect of the relatively high mechanical and hydraulic inertias of the turbocharger.

The use of the turbine energy boosting device seems to have little effect on the engine acceleration response. This could probably be improved by increasing the amount of 
energy added. However, it is observed that the dynamometer load does not reach values comparable to previous cases. Besides, the load torque stays longer at its highest value before starting to decrease. It may be understood that the action of the device lags the engine acceleration so that the net effect is to increase the turbocharger speed without having a positive impact on the boost pressure.

The results obtained when using air injection and exhaust combustion concurrently, show that the engine acceleration response is very much similar to that with air injection alone. The behavior of the measured parameters follow the same trends as explained before.

Figures (4 to 6 ) show the results of acceleration tests at higher initial brake torque. The arguments, presented earlier, hold good for analyzing the results given.

\section{Load Acceptance Tests}

Eigure (7) shows the results of load acceptance test carried out on the normally aspirated engine. The recorded data indicates that the engine speed quickly drops as the load is icreased. This drop continues until a new balance between the engine and brake torques is reached. During this period, the injection pump rack is pushed against its mechanical stop, a direct result of the operation of the variable speed governor. Consequently, the maximum possible amount of fuel is injected inside the cylinder. As the engine torque increases and starts to overcome the brake load, the fuel rack is pulled back which decreases fueling and limits the engine developed torque. This transient action takes almost 5 to 6 seconds when the initial brake torque is $150 \mathrm{~N} . \mathrm{m}$. With higher values, the engine reaches its final speed in progressively longer periods. It is also observed that the final speed "is higher with increased initial load, which could be attributed to the better engine torque backup at higher governor setting.

Load acceptance tests were carried out on the turbocharged -engine when the initial brake torque was set to $120 \mathrm{~N} . \mathrm{m}$. The results obtained are shown in fig.(8).

The response of the turbocharged engine to the sudden load application seems to be very much similar to that of the naturally aspirated engine. The speed drops to its final steady state value at almost the same period of time. It is interesting however, to notice the change in the rate of increase of turbocharger speed when the energy boosting devices are used. It is evident from the displayed results, that the turbocharger speed increases more rapidiy, especially in the case of exhaust combustion. It is also noticed that the boost pressure reaches its highest value during the engine transient operation. It is expected 
however, that the boost pressure drops to its final steady value after a few more seconds.

The transient response of the turbocharger is greatly improved due to air injection and exhaust combustion. Despite that, the engine response to sudden application of load does not seem to benefit. This can be explained by the decreasing demand on air supply as the engine speed decreases during the first 5 to 6 seconds. The energy boosting devices are operated only in the first 2 seconds of this period, and therefore, with little effect.

Figures ( 9 to 11 ) give the results of load acceptance tests when the initial brake torque was set to values higher than $120 \mathrm{~N} . \mathrm{m}$. It can be seen that the engine developed torque increases more rapidly when the energy boosting devices are applied. This is due to the increased fueling caused by the action of the 'aneroid' at manifold pressures higher than 1.1 bar.

\section{CONCLUSION}

Two separate techniques were applied to improve the transient response of the turbocharged diesel engine. First, injecting compressed air in the induction manifold for a short period in order to satisfy the suddenly increased demand on air supply as the engine accelerates. In the second method, fuel and air were injected and ignited inside a special combustion chamber when a sudden increase in engine speed or load was required. The combustion products under high pressure and temperature were allowed to discharge from the chamber into the exhaust manifold as close as possible to the turbine entry. This resulted in boosting the energy available to the exhaust turbine and thus improving the transient response of the turbocharger.

Experimental measurements proved that the transient response of the turbocharger was greatly improved due to air injection and exhaust combustion. Despite that, the engine response to sudden application of load did not seem to benefit. This could be explained by the decreased demand on air supply as the engine speed decreases during the first 5 to 6 seconds of the transient operation. The energy boosting devices were operated only during the first 2 seconds of this period, and therefore, with iittle noticeable effect. On the other hand, it is concluded that aif injection in the intake manifold significantly improves the turbocharged engine acceleration response. Jsing exhaust combustion to increase the energy available to the turbine does not produce comparable results. This is attributed to improper timing of exhaust combustion which needs further investigations. 


\section{REFERENCES}

[1] Marzouk,M.A., "Transient Response of Turbocharged Diesel Engines"., PhD.Thesis, London University, June (1976).

[2] Zinner,K., "Turbocharging of Internal Combustion Engines". Berechnungen. Ausfuhrungen. Sprnger-Verlag, (1975).

[3] Watson, N.S. and Janota,M.S., "Turbocharging the internal Combustion Engines". The Macmillan Press Ltd., London, (1982).

[4] Shahin,M.A., "Performance of High Output Turbocharged Vehicle Diesel Engines". PhD. Thesis, Imperial College of Science \& Technology, London (1982).

[5] Watson, N., "Turbochargers for the 1980's, Current Trends and Future Prospects". SAE, 790063.

[6] Winterbone, D.E., Benson,R.S. \& Kenyon, P., "Transient Response of Turbocharged Diesel Engines. Part 1, A Comparison of Two Methods of Improving Response". SAE 770123 .

[7] Ledger, J.D., Benson,R.S. \& Eurukawa,H., "Improvement in Transient Performance of a Turbocharged Diesel Engine by Air Injection Into the Compressor"., SAE 730665.

[8] Timoney, S.G., "High Pressure Turbocharging of 2-Stroke Engines"., SAE 690747. 


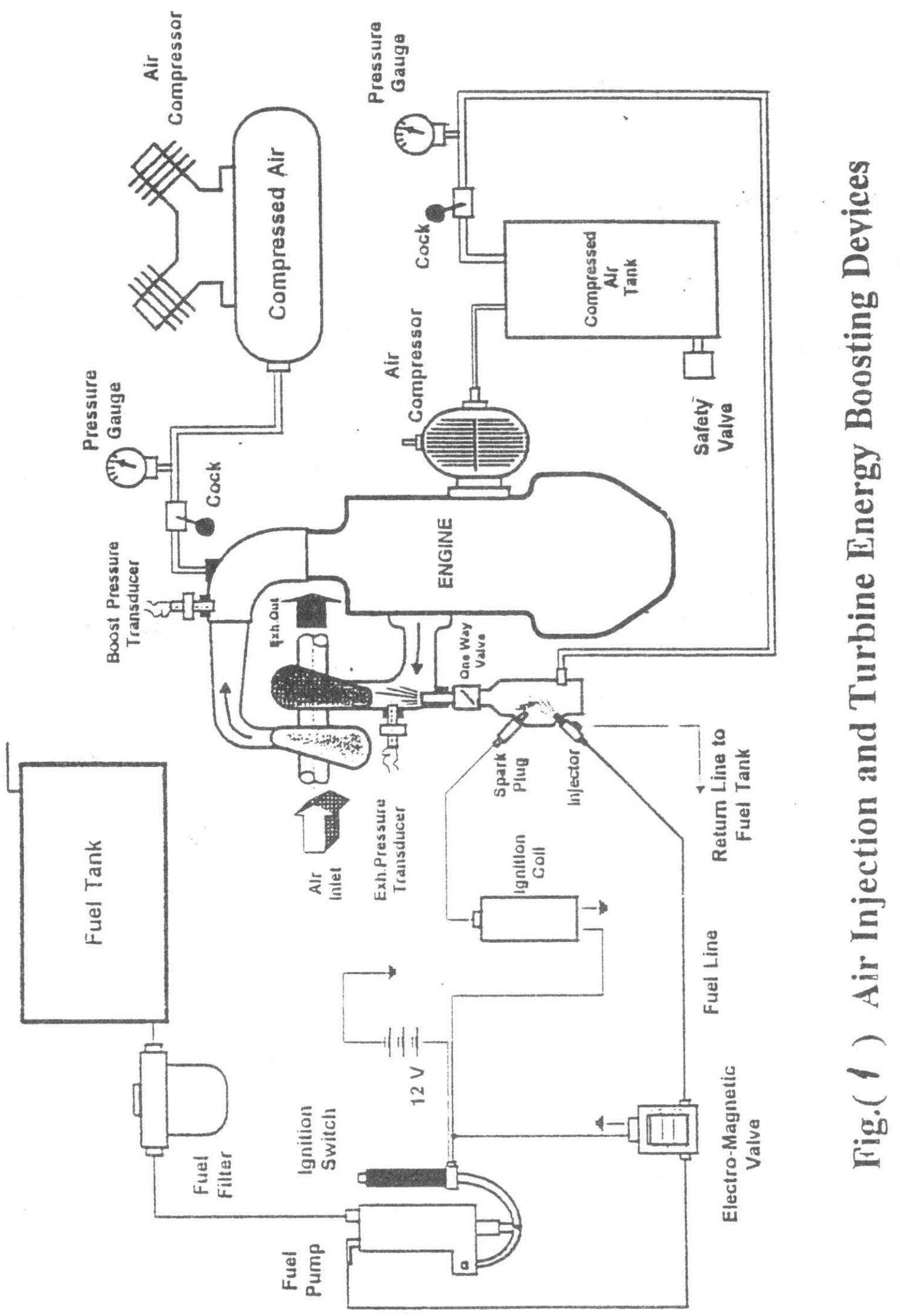



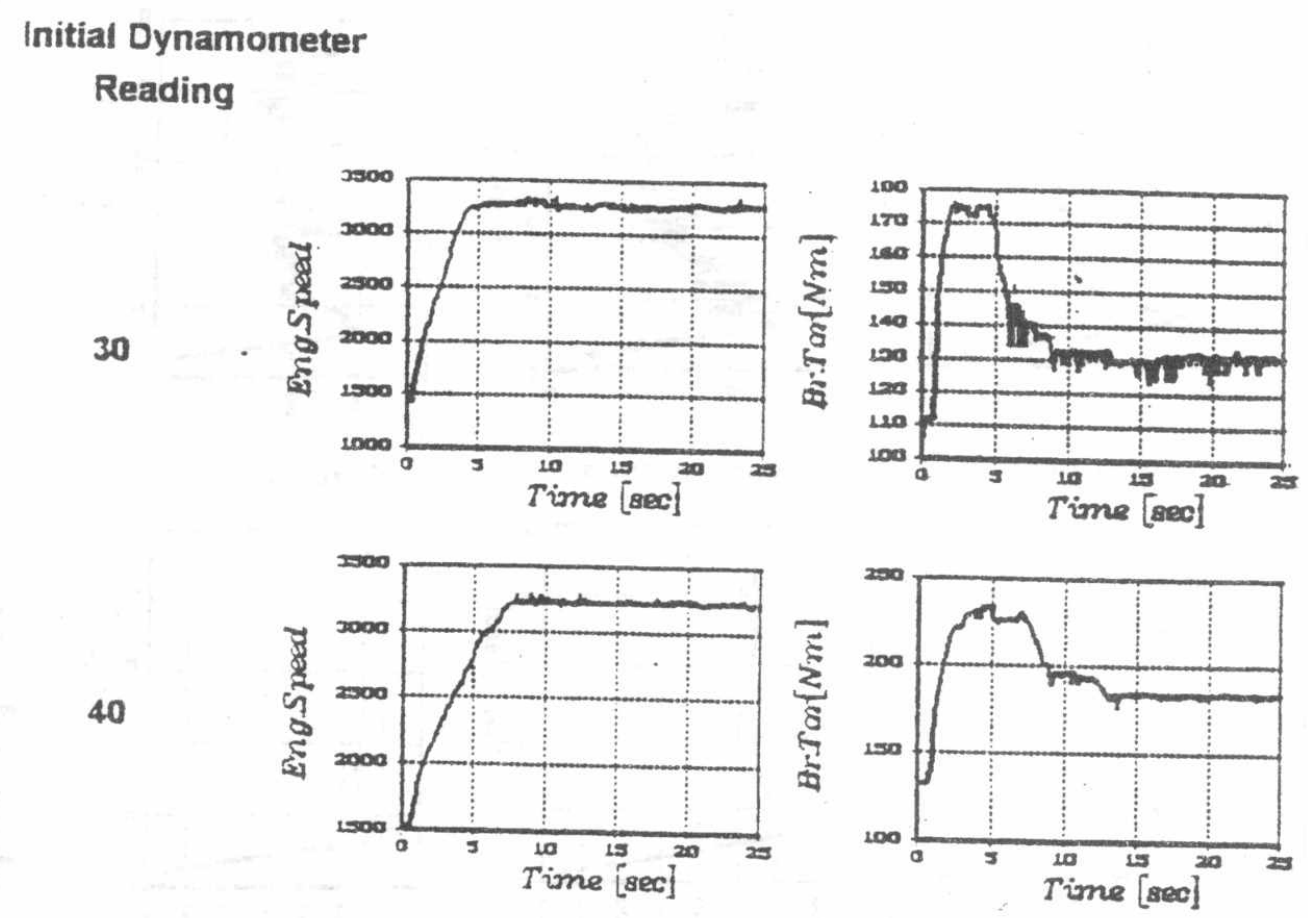

40
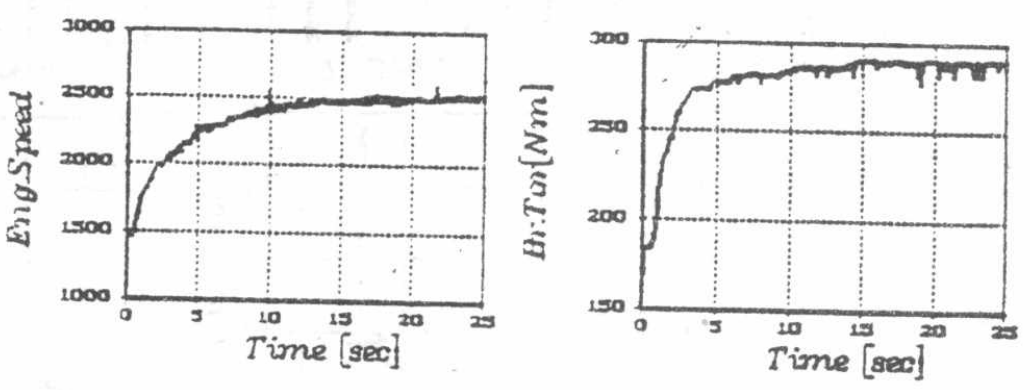

60
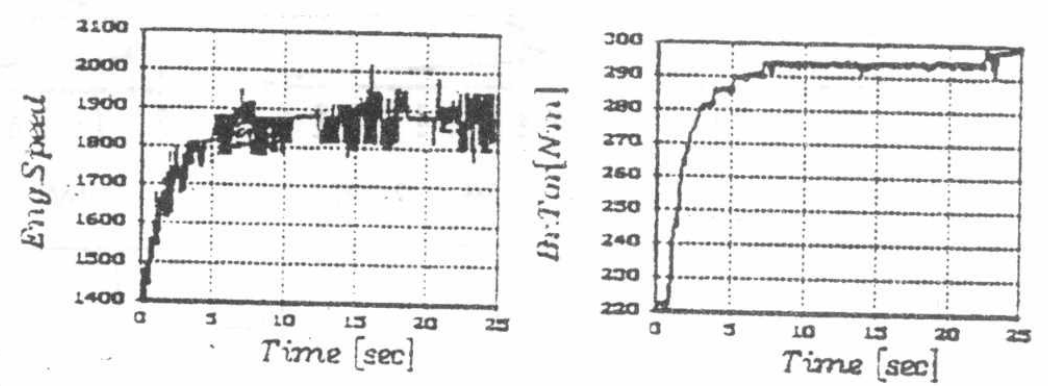

Fig.( 2 ) Acceleration Test Results

Initial Engine Speed $=1500 \mathrm{rpm}$

Vormaally Aspirated Engine 

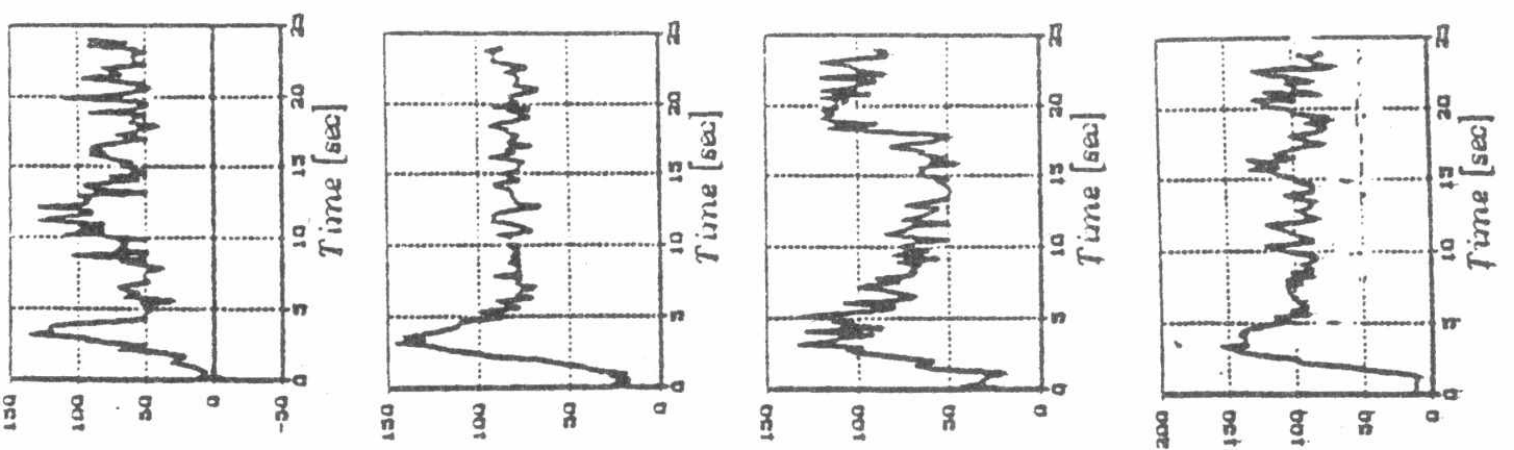

${ }^{8}$ Hurue : 20

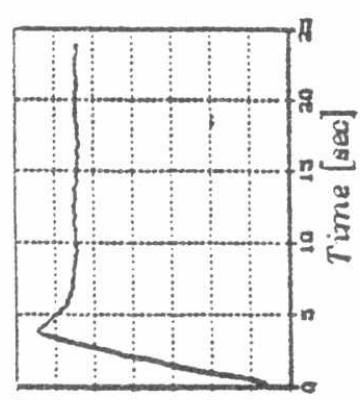

BHurue idd

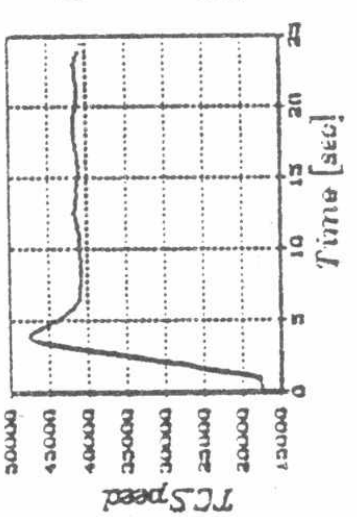

BHrune मdg

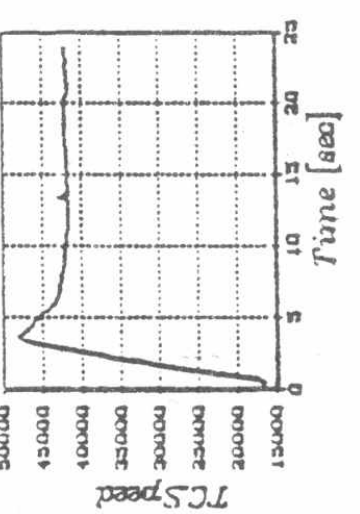

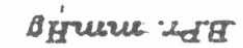

mInth

poods 52
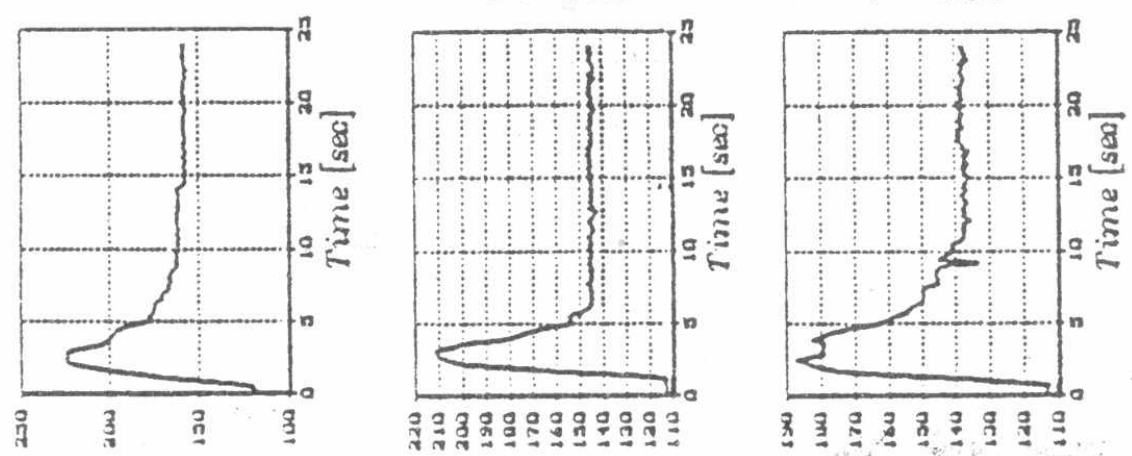

$\left[\mu_{N}\right\}_{0}[4]$

$\left[\mu N \mu_{0} r x\right.$
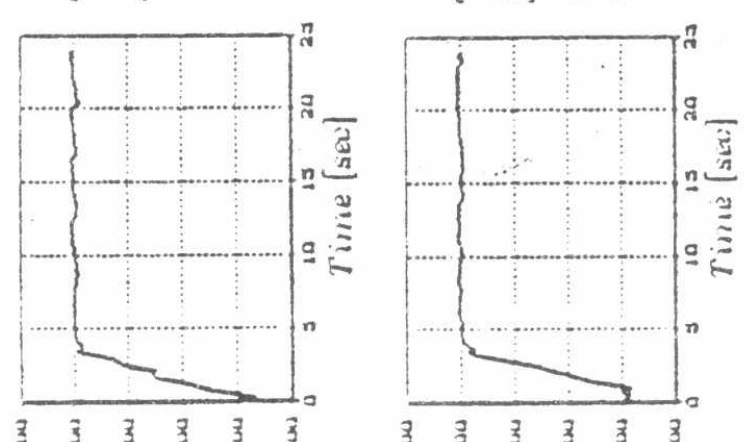

paodstug

prodsdug

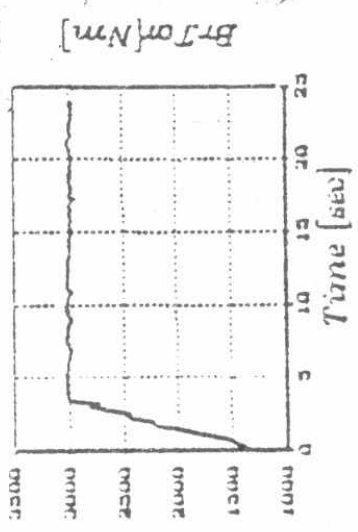

pood 534 T

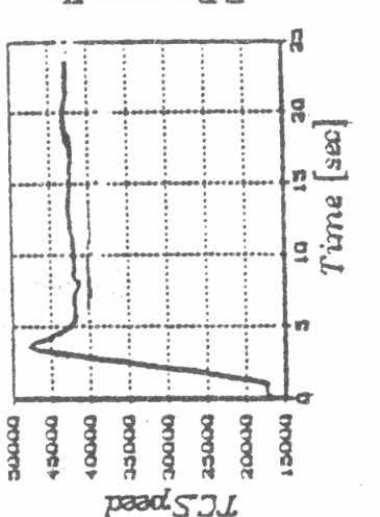

유

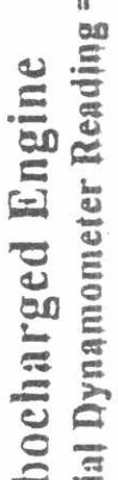

$\equiv$

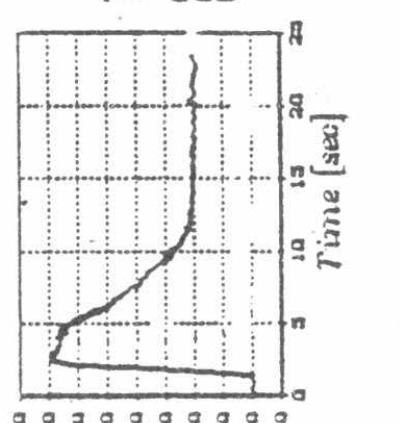

E

든

幽

항

¿

豆焉

픈

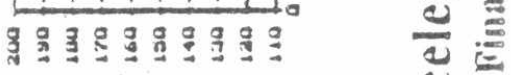
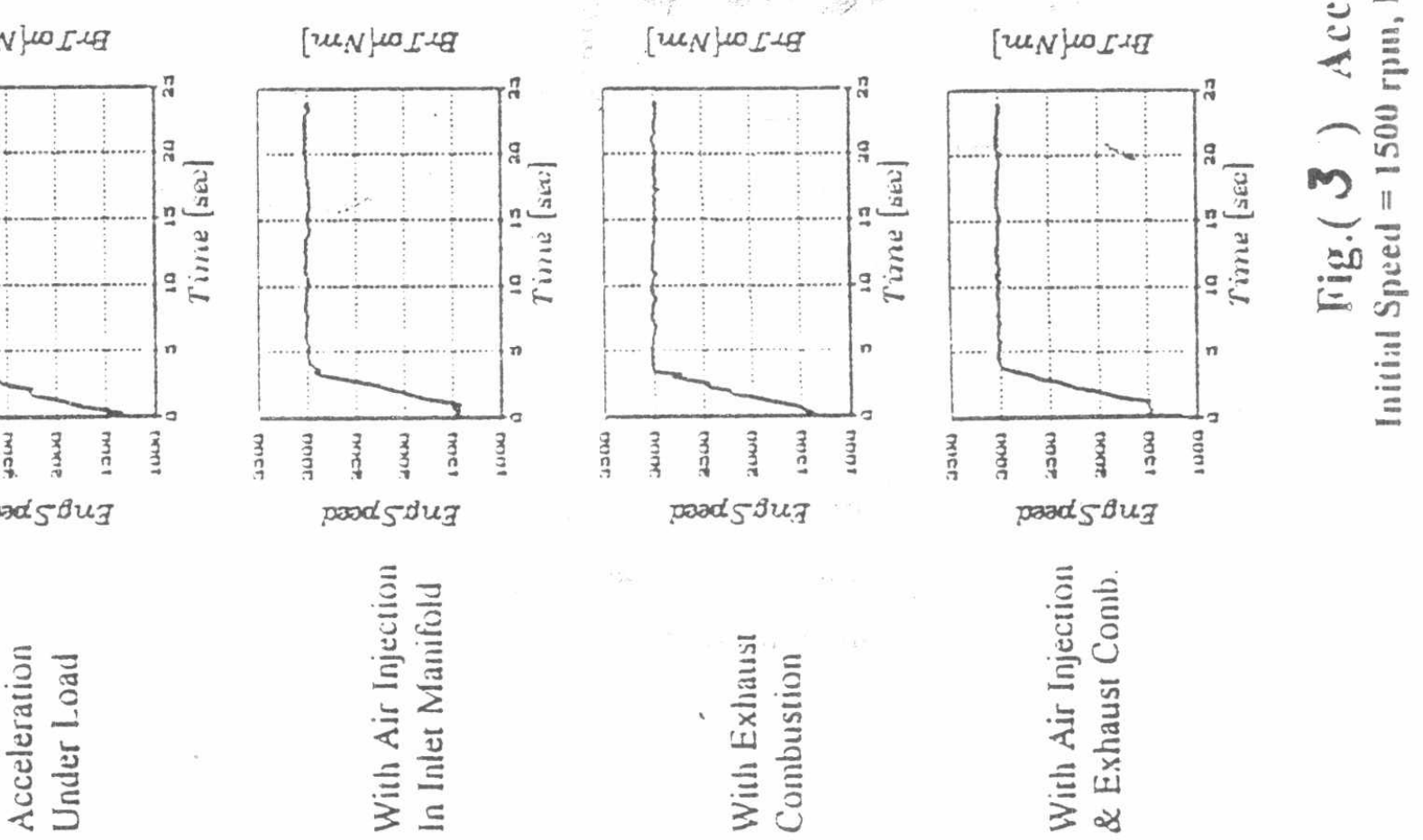

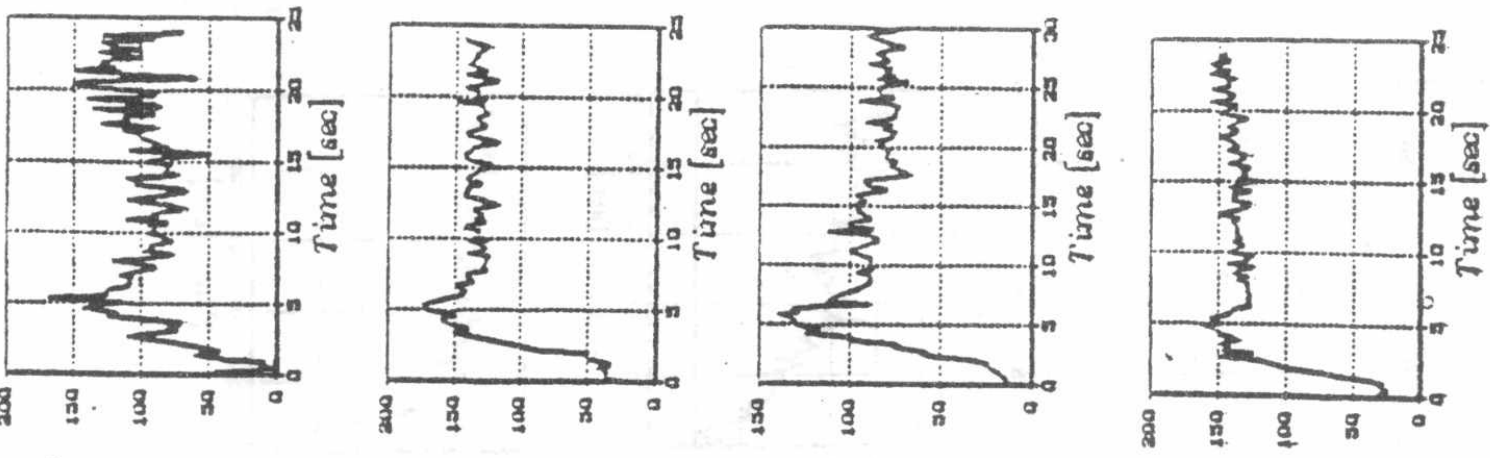

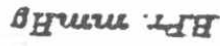

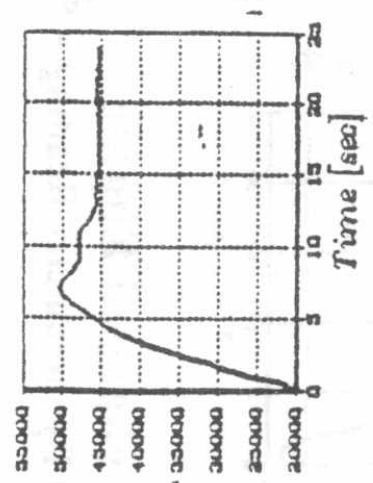

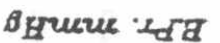

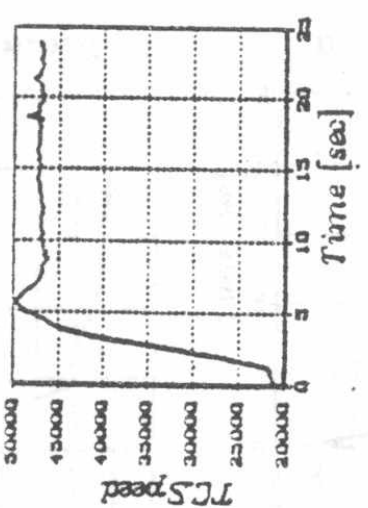

Bgrees :
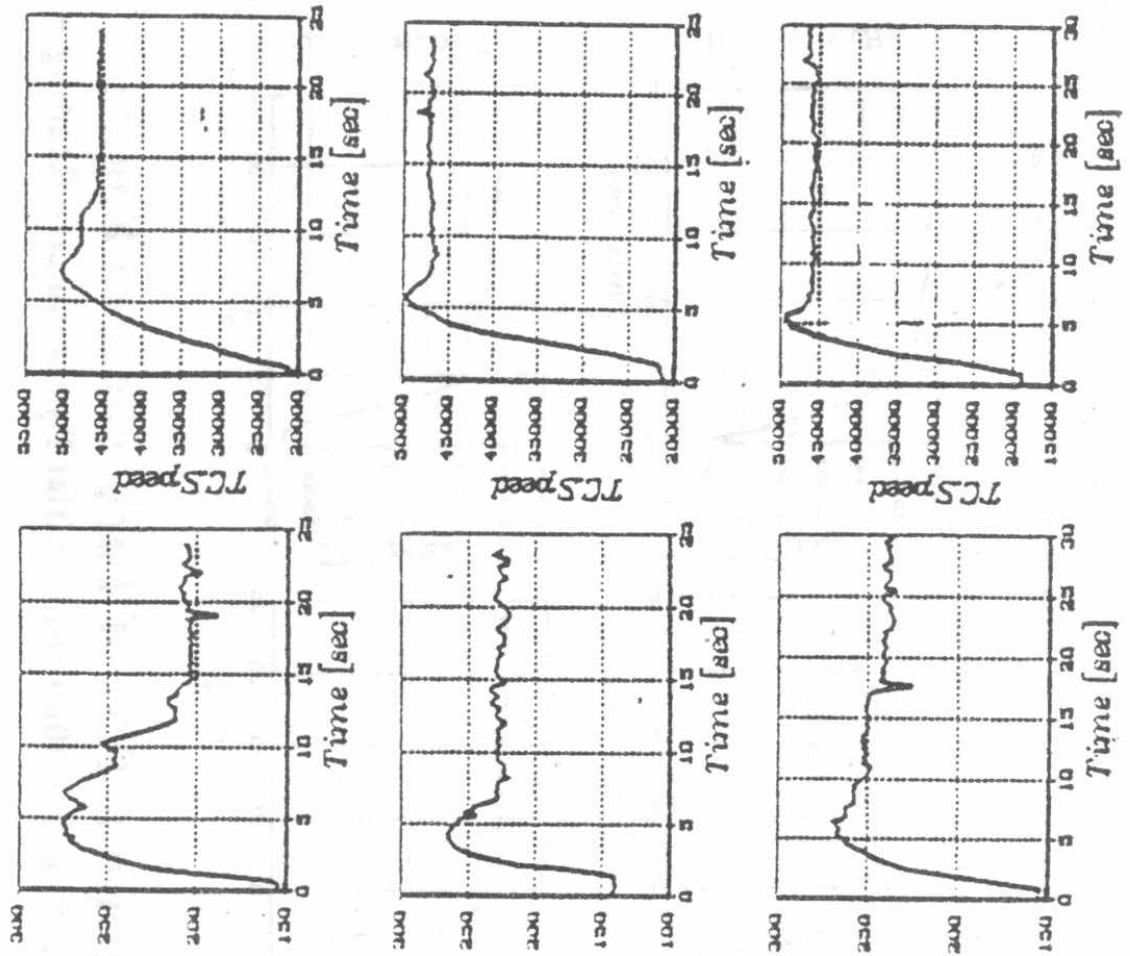

Btrucue :

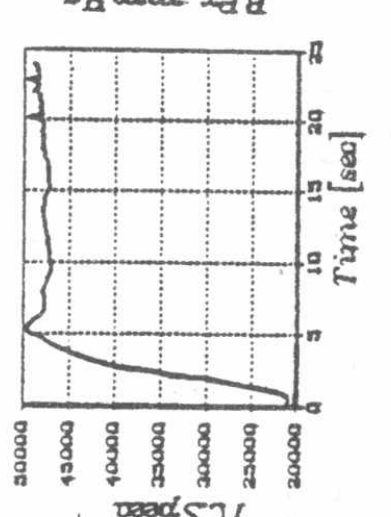

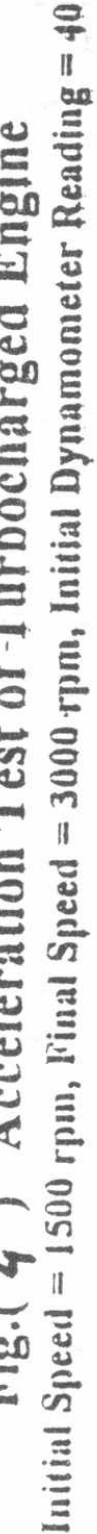

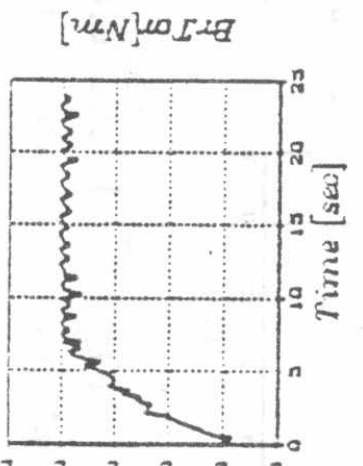

[un]wrig

$\left[u \mu_{N}\right\} \omega_{L}<\mathcal{G}$
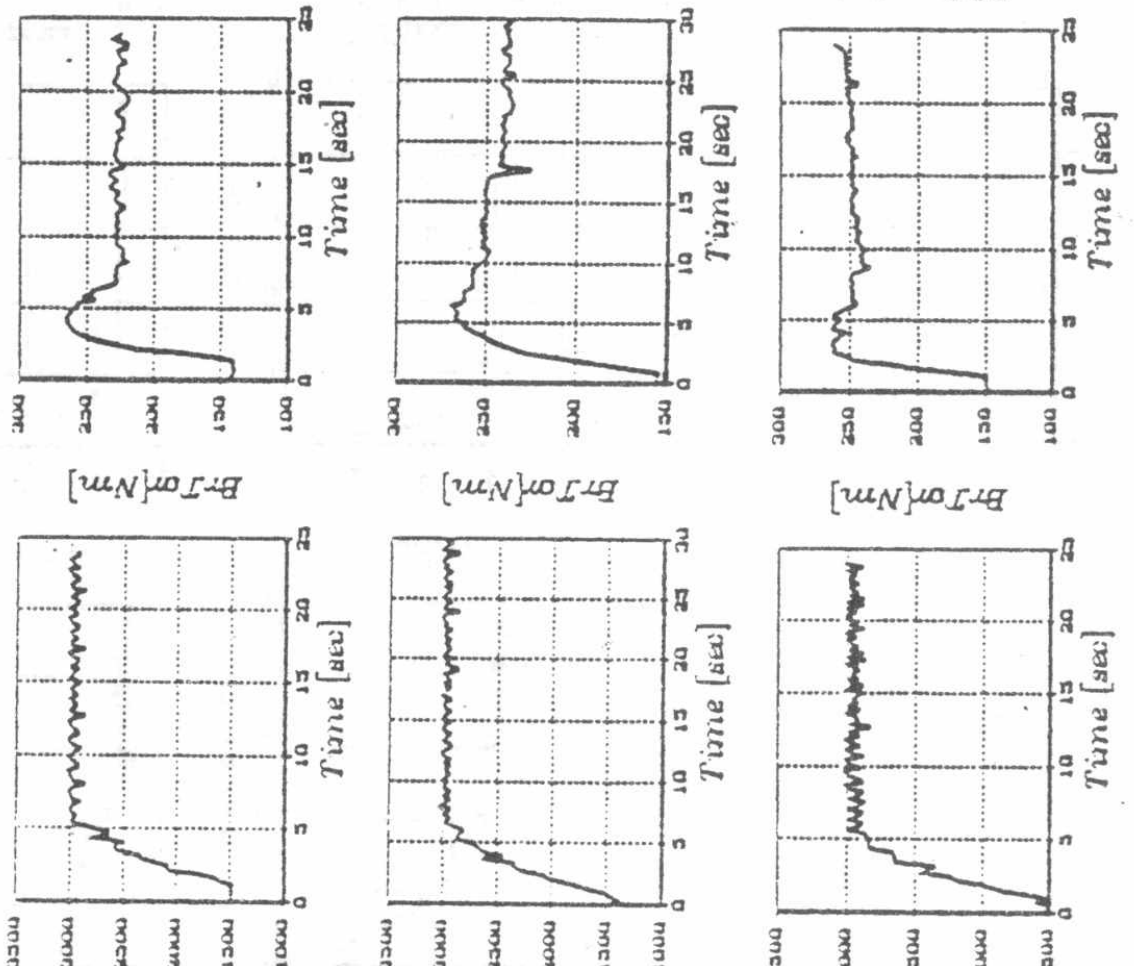

$\left[u_{N}\right]_{5}-4$

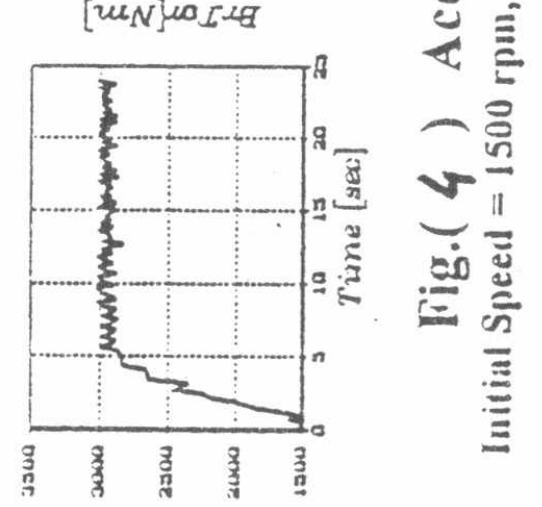

$\operatorname{cod} 5$ one

padsthez

pads 5 duc]

prodstoreg

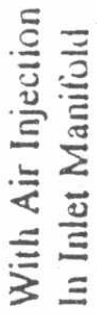

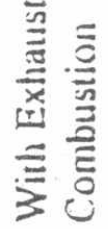

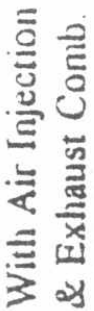




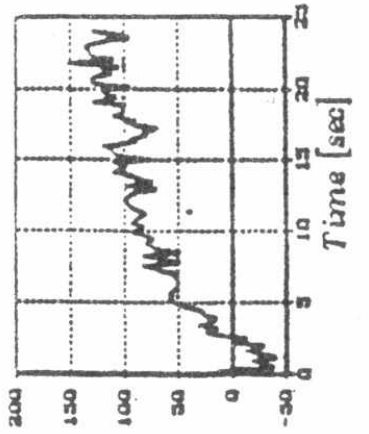

Btrucue : 28

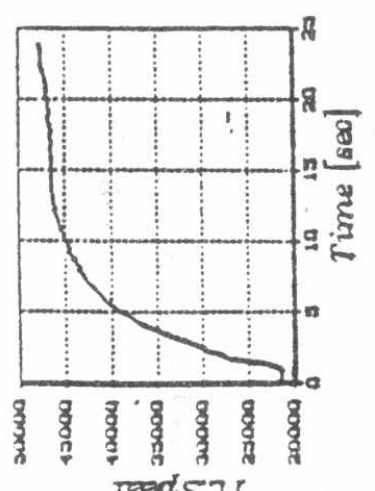

50015JL

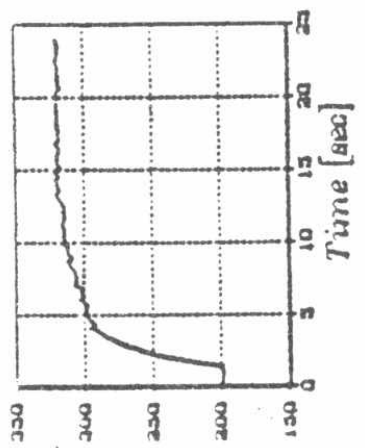

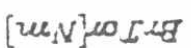

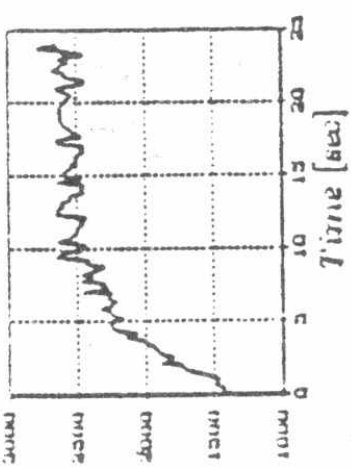

poodsthus

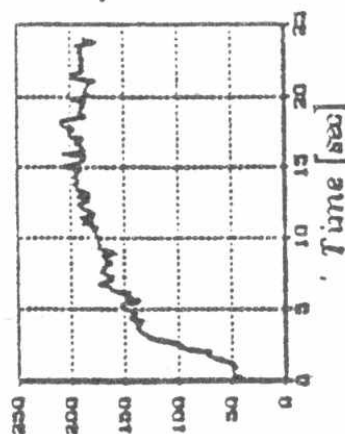

$B_{\text {Hrure }}:$ d

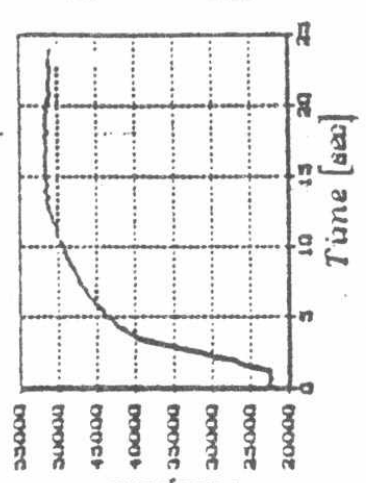

مrods

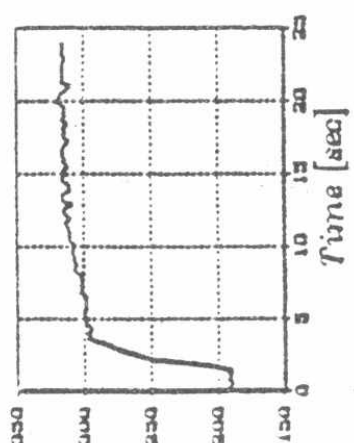

[uN] L L -4

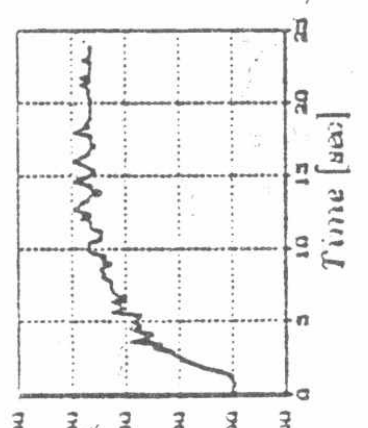

pardsdus

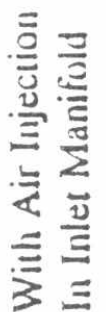

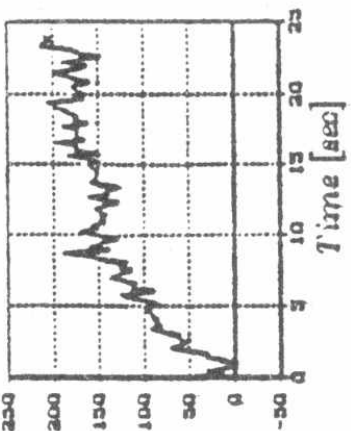

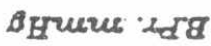

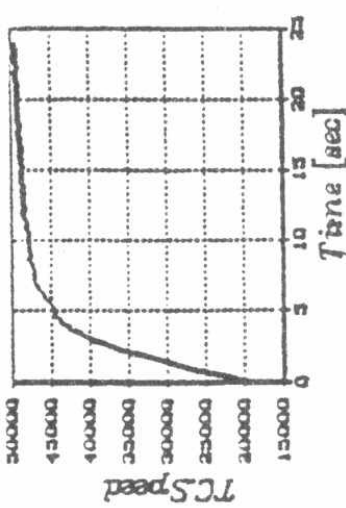

poodSJL

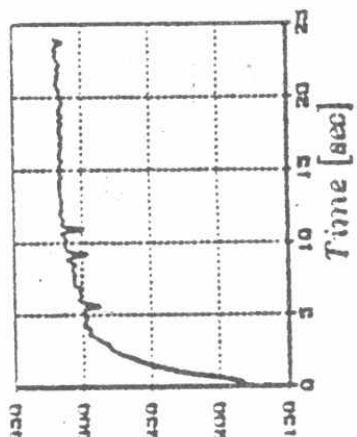

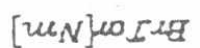

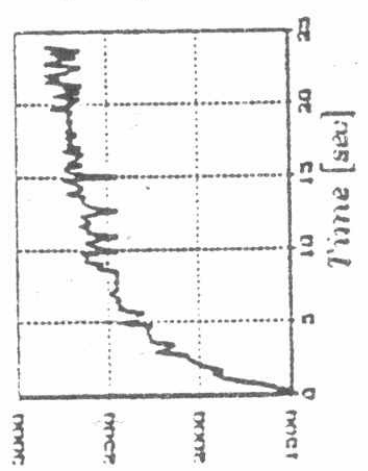

poods 5 dut

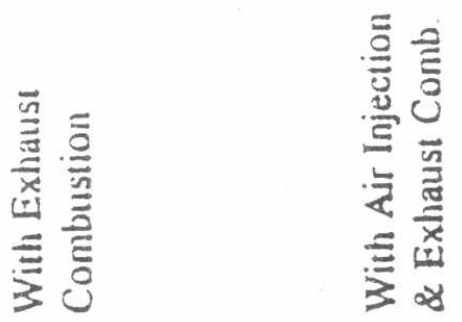

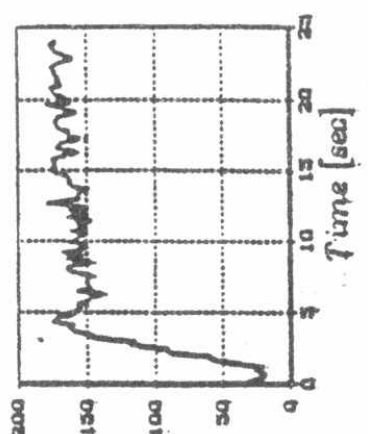

BHuru: मd
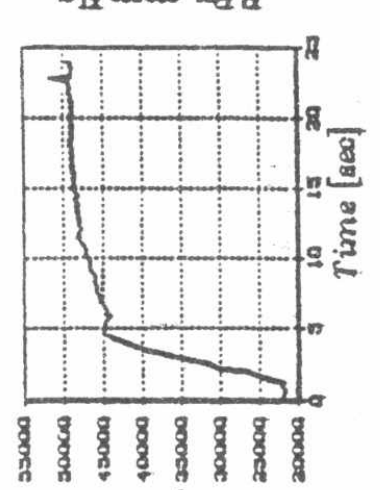

poodSILL

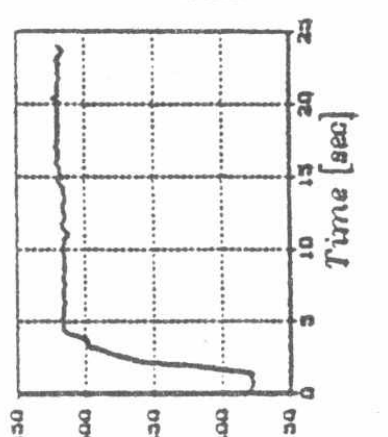

$\left[u_{N}\right\}_{0}[\mathrm{~g}$

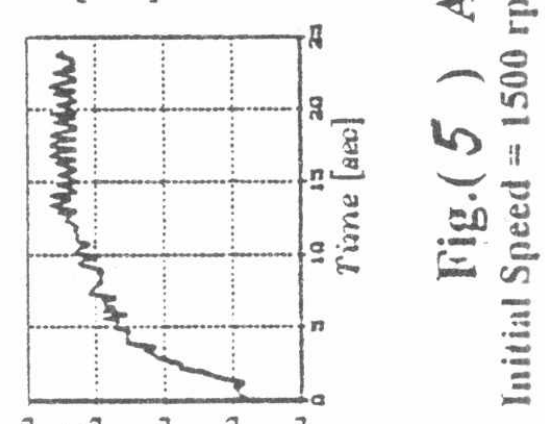

竞灵 
Proceedings of the $7^{\text {th }}$ ASAT Conf. 13-15 May 1997

\begin{tabular}{|l|l|}
\hline PR-4 & 471 \\
\hline
\end{tabular}
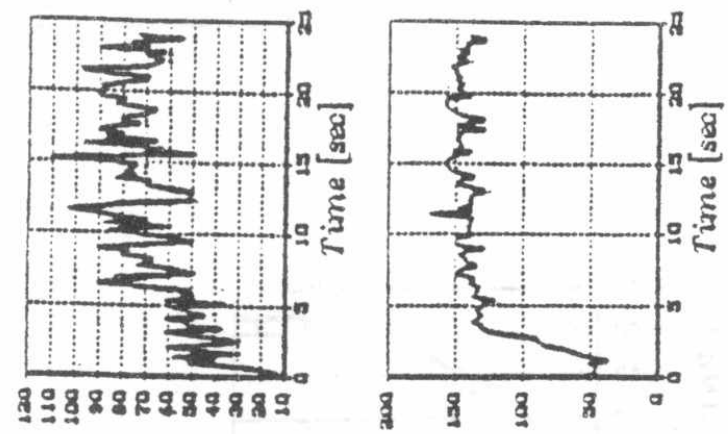

BEruser :

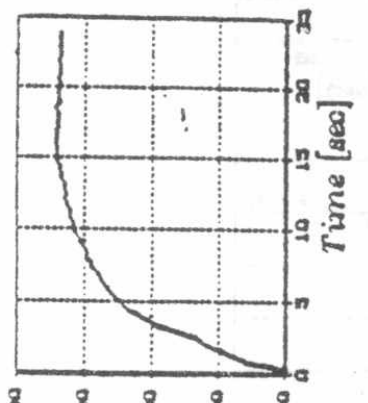

Btrucue : 2 da
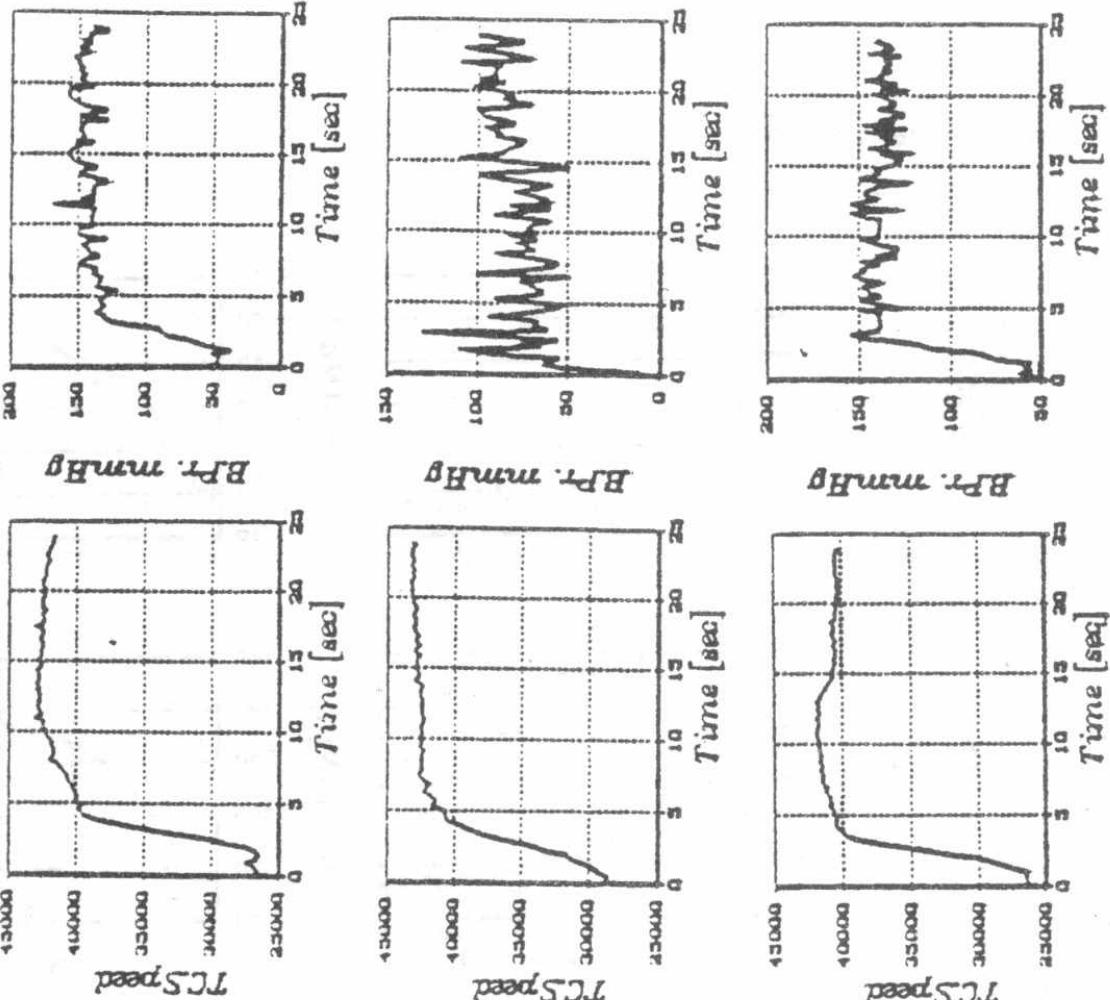

B

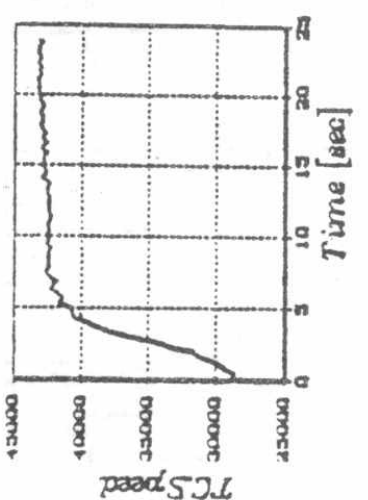

Otrucuk :्वृ

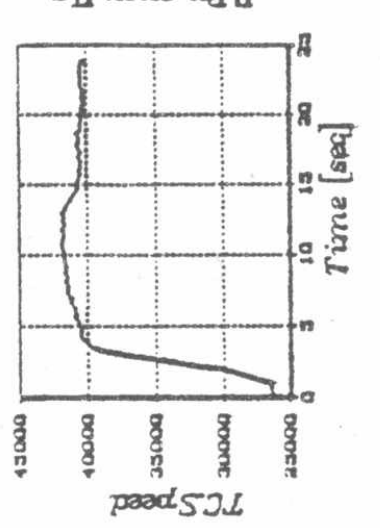

5
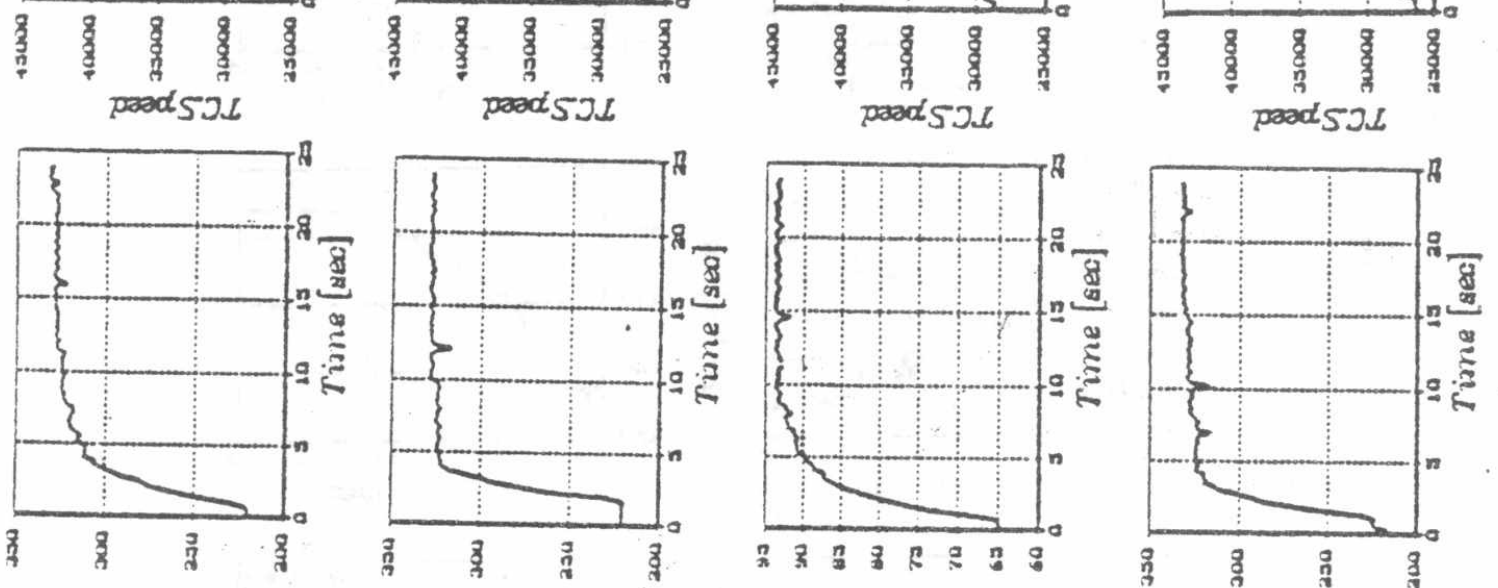

딜

$\left[u_{N}\right] \log _{\text {L }}$

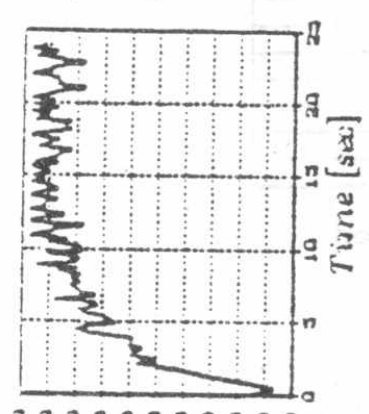

$\left[u_{N}\right] \omega_{5}-d$

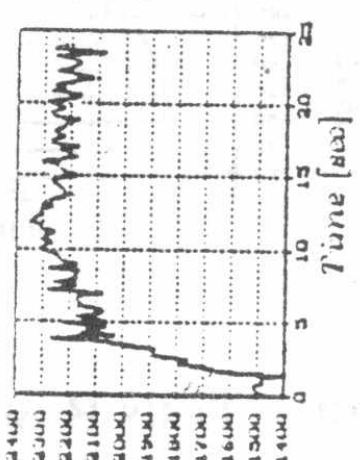

Burporata

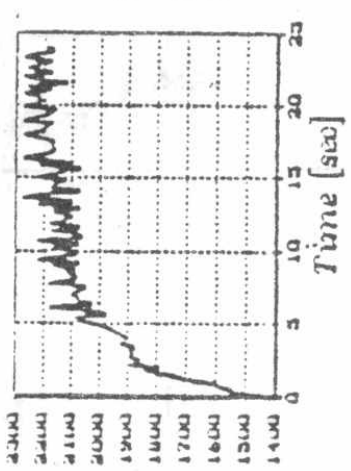

[unverstg

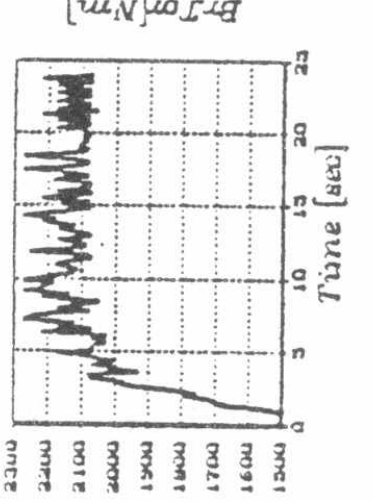

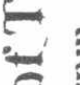

e

क

(4)

$=\frac{11}{2}$

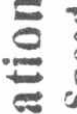

$\frac{2}{4}$

$4=$

¿

-

6

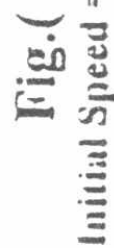

paodsous

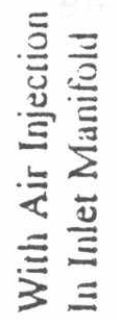

poodsbur

paadsoluz

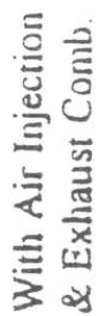


Intial Dynamometer

Reading

30
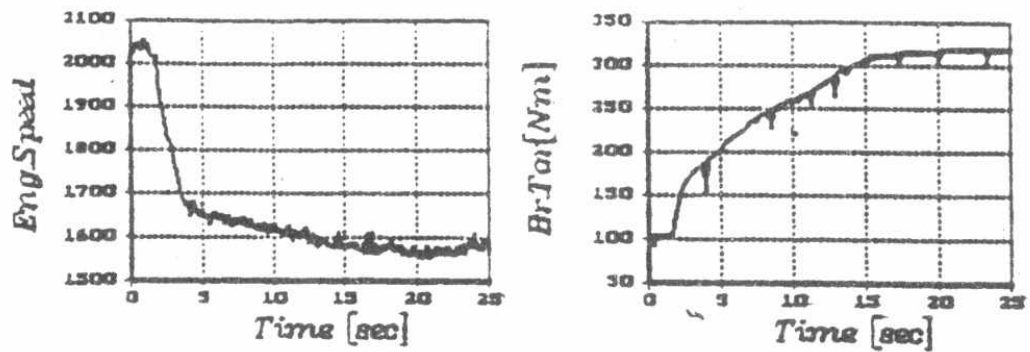

40
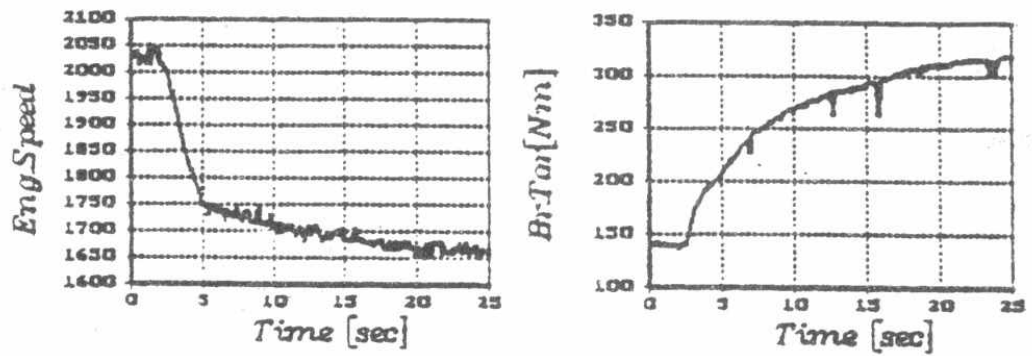

50
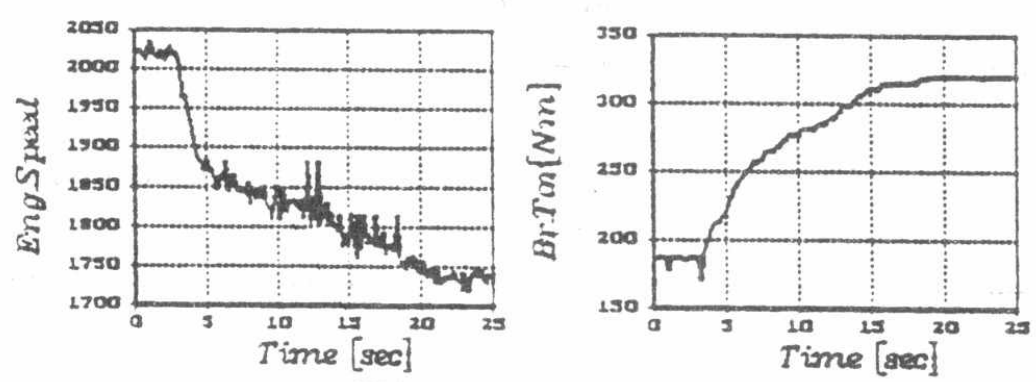

60
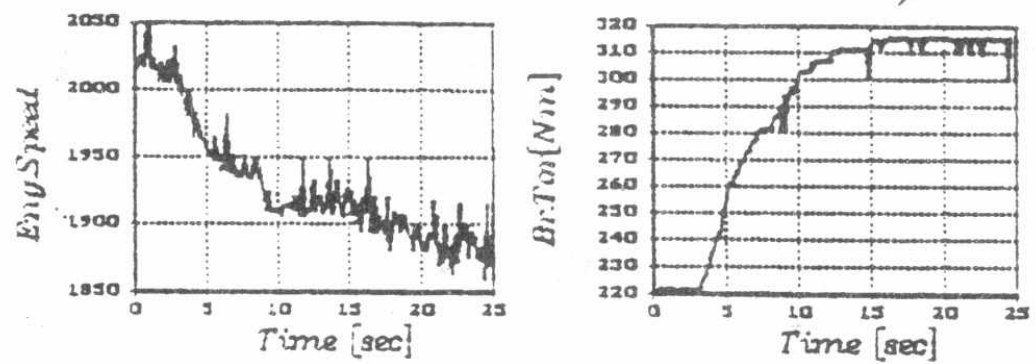

Fig.(7) Load Acceptance Tests Results Initial Speed $=2000 \mathrm{rpm}$

Normally Aspirated Engine 


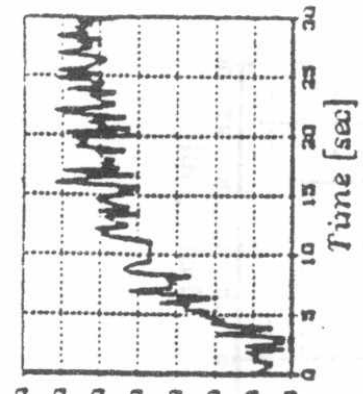

8 व

B Hrue :

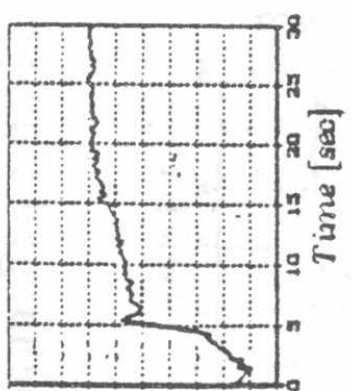

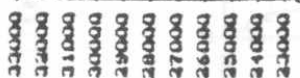

prod.5.3.1.

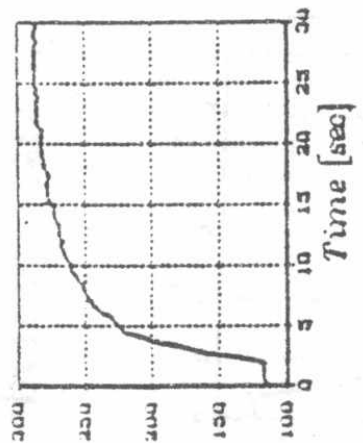

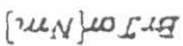

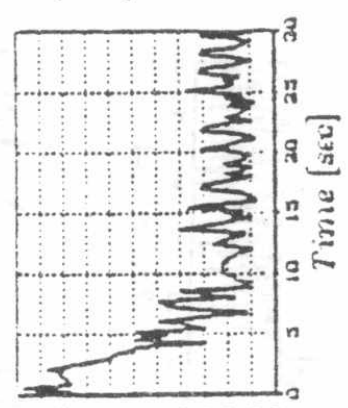

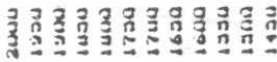

raods 5 fiug

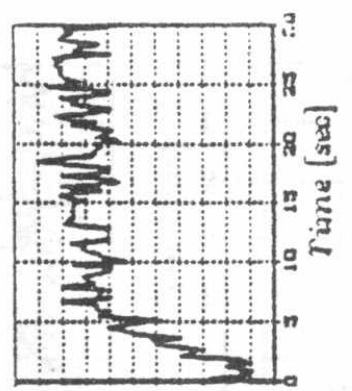

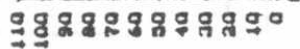

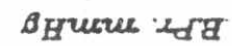

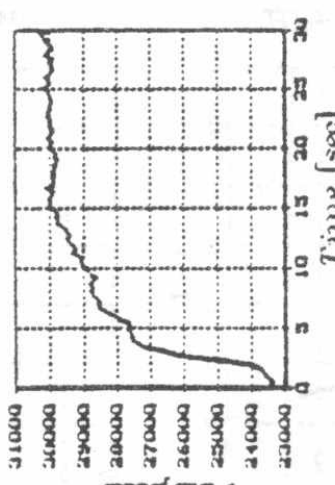

pood.5.L

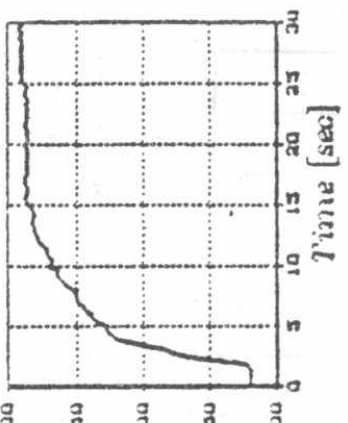

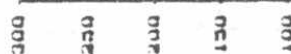

[univorag

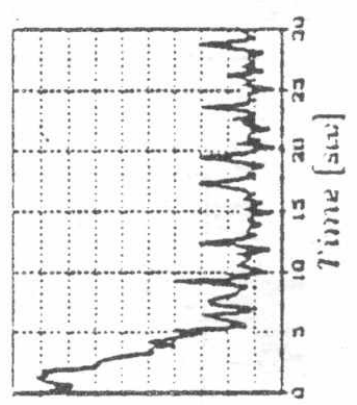

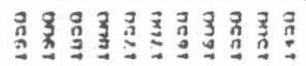

pordsolut

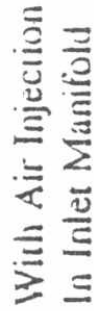

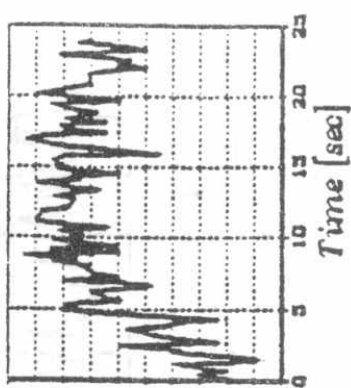

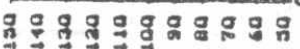

Brrueve idg

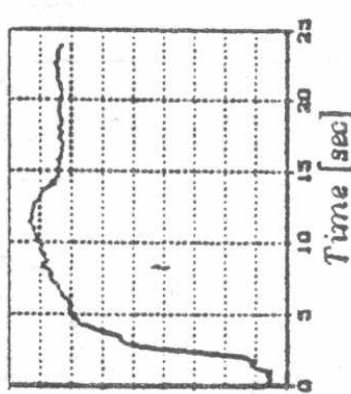

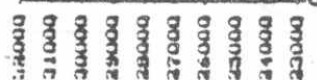

pood SJL

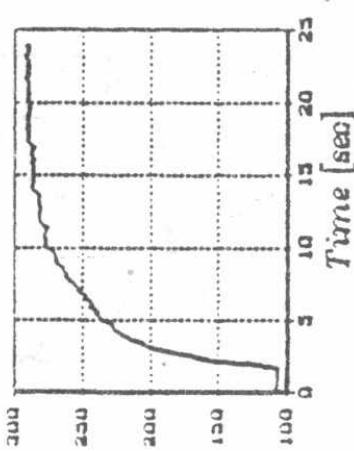

$[u, v j w i g$

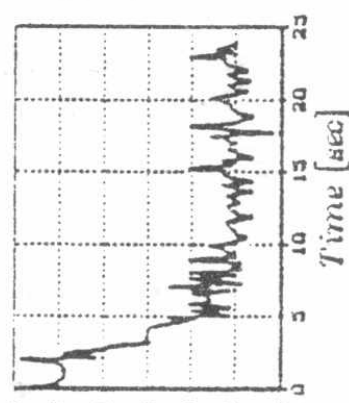

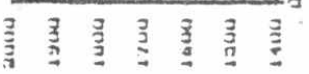

एखads buz

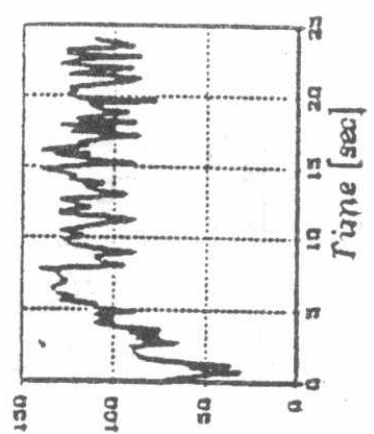

$\theta_{\text {Huxu : }}$

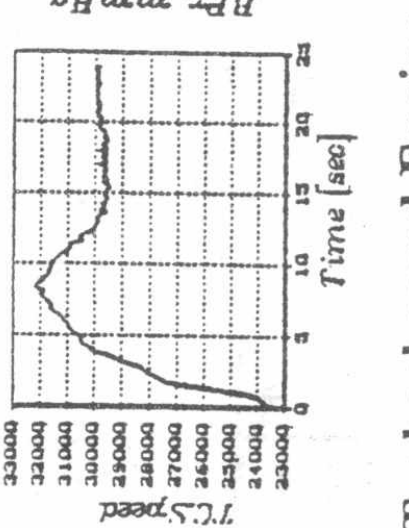

竞 흔 $\equiv$

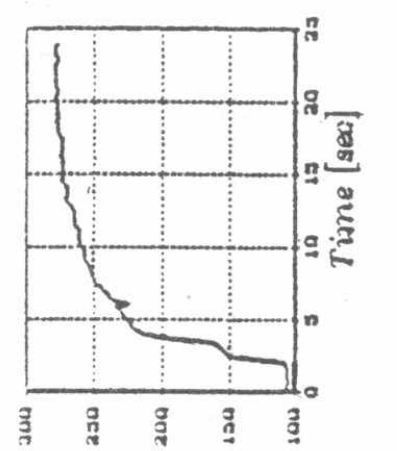

○

क ซ (2) ‥ e E 용 ¿ I. II

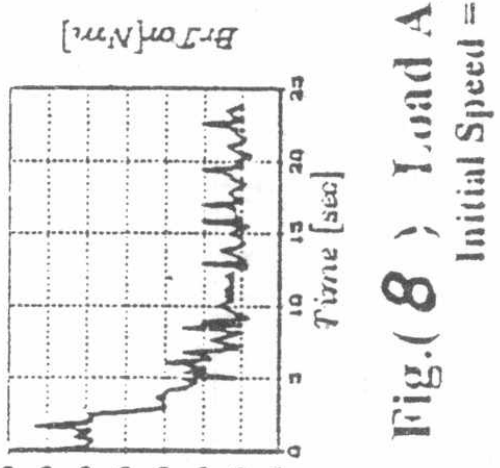

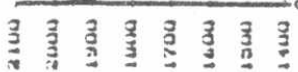

poadsoug

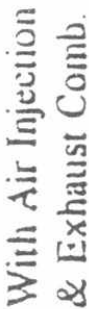




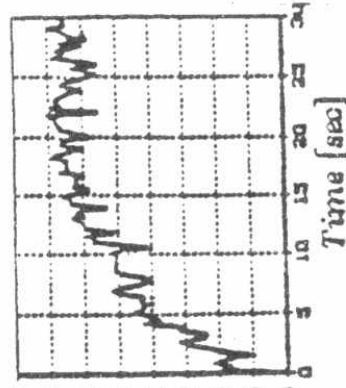

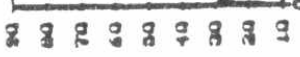

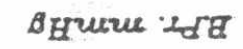

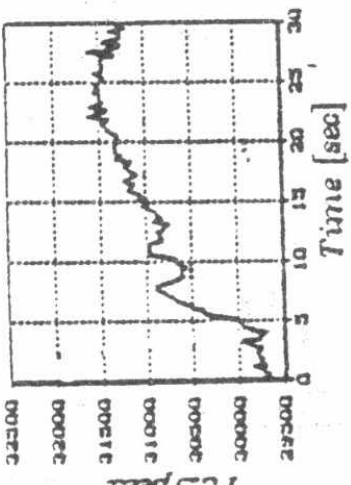

pads 2.

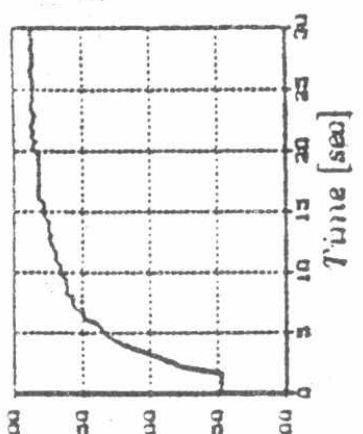

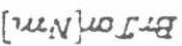

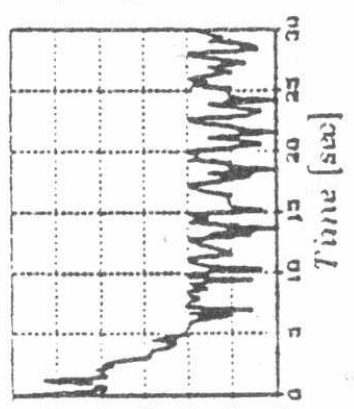

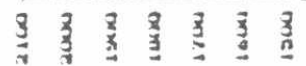

poodstouca
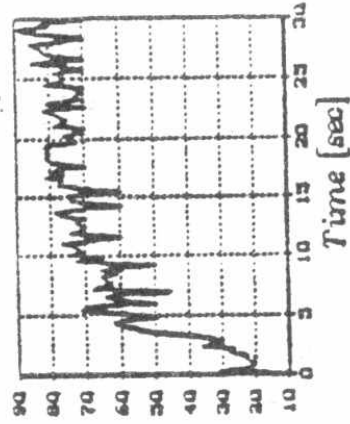

Bष

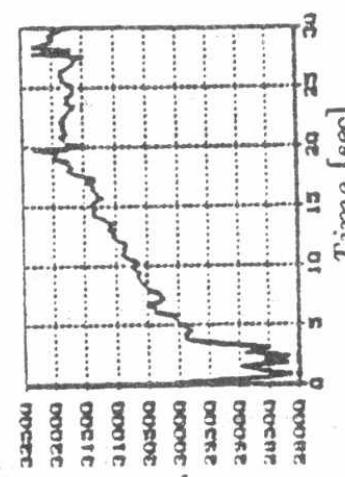

paodSJL

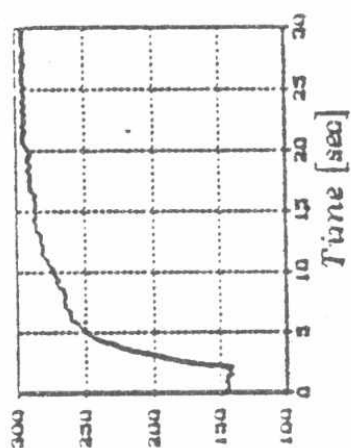

$[u, N] \omega$ L 2 G
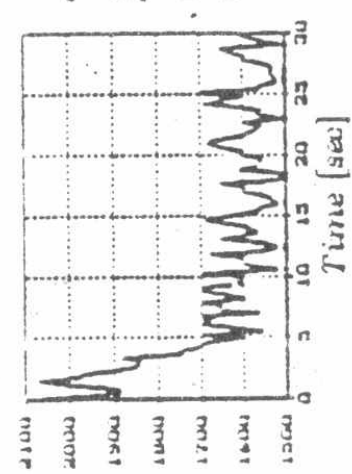

poodstuz

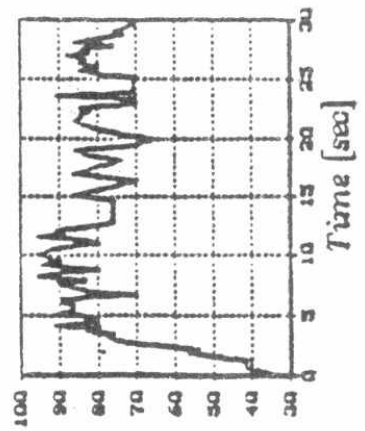

BErucus :
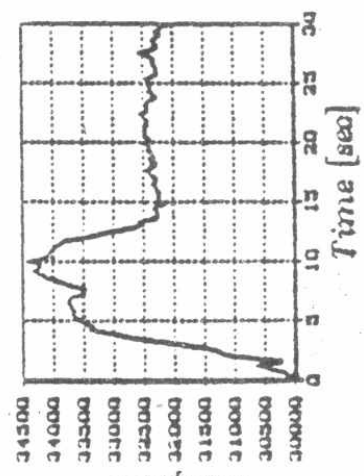

paods 3.6

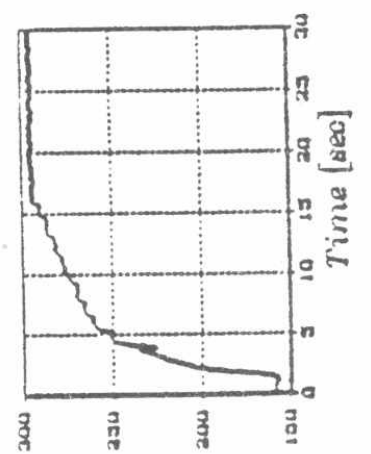

[UN]NDEG

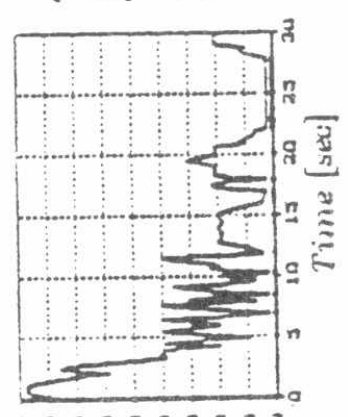

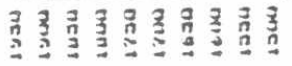

paadsduz
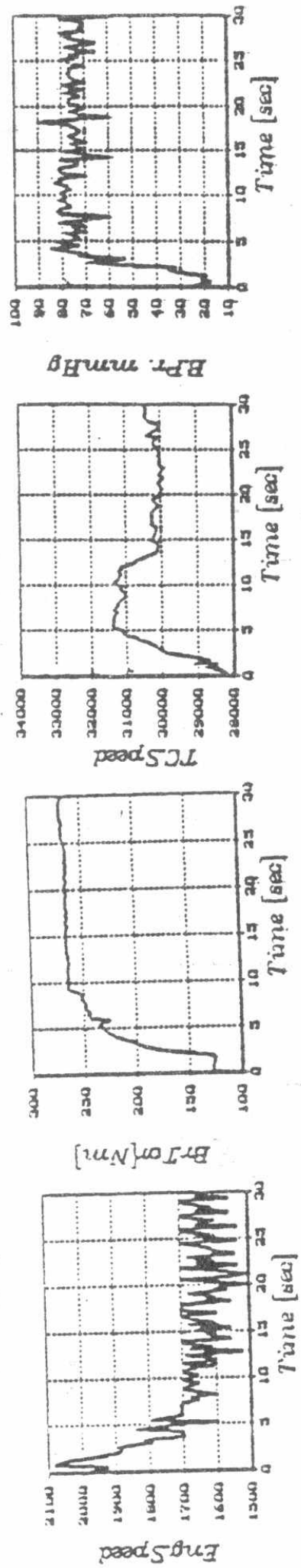

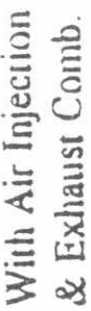

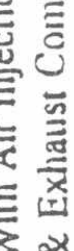

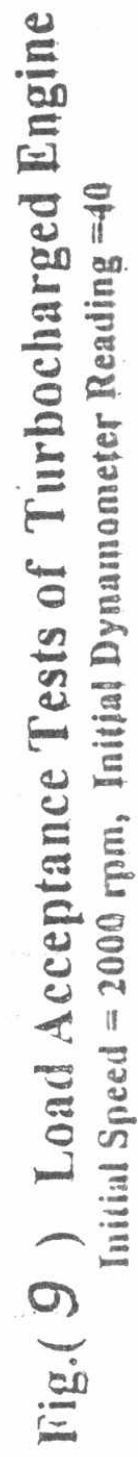

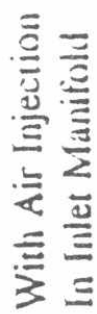

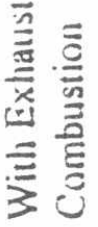


Proceedings of the $7^{\text {th }}$ ASAT Conf. 13-15 May 1997

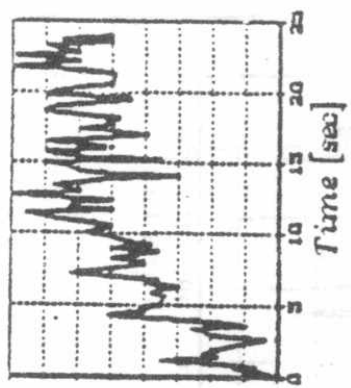

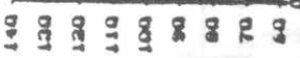

Bमturu यूd

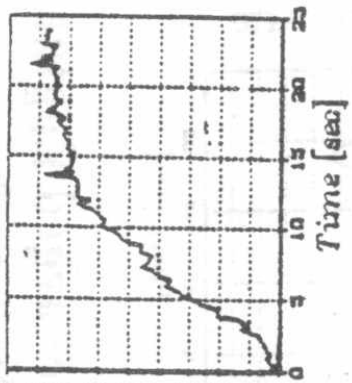

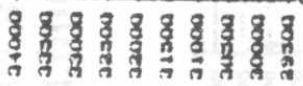

pood.5.2J.

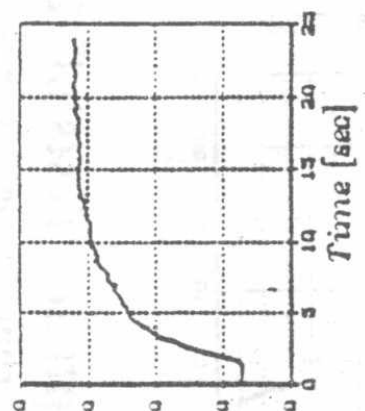

量亭亭

[un\}ersta

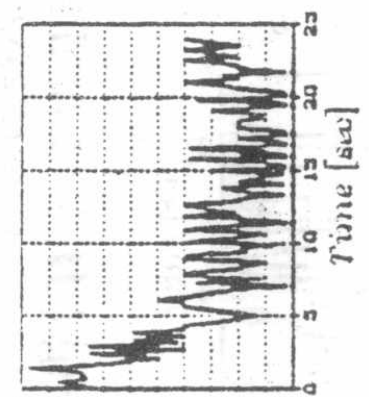

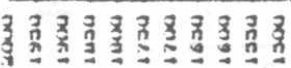

paods 5 dug

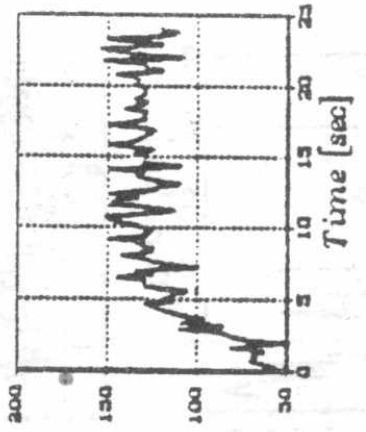

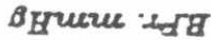

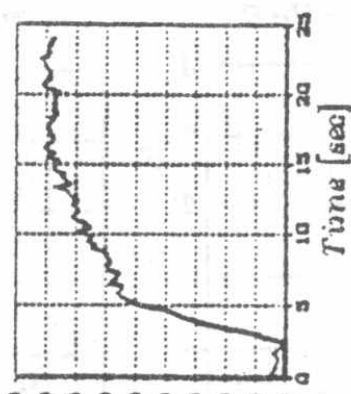

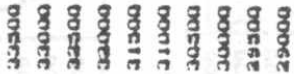

pad.5.2.

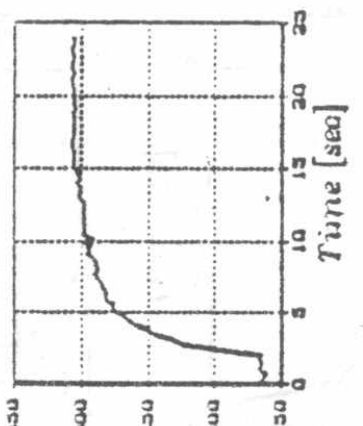

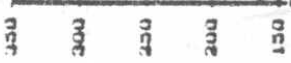

[UN? LOSH]

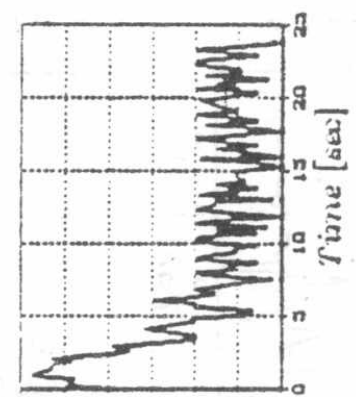

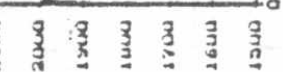

poods sut

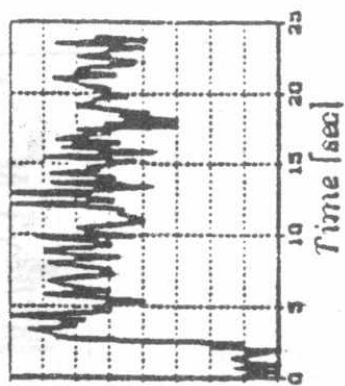

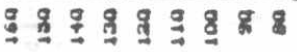

BHurue :
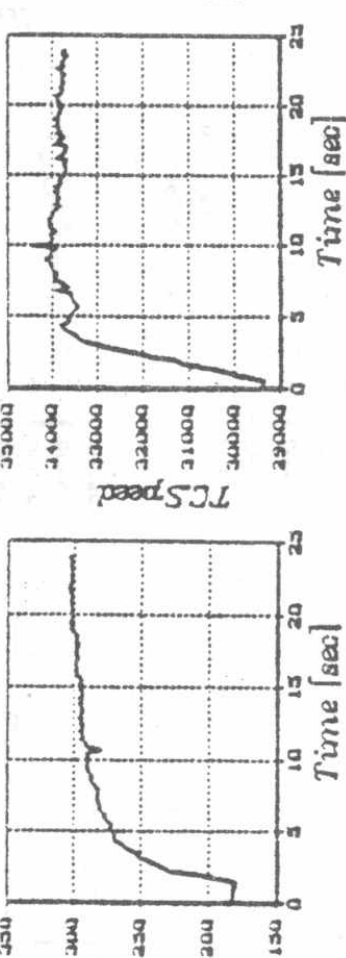

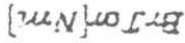

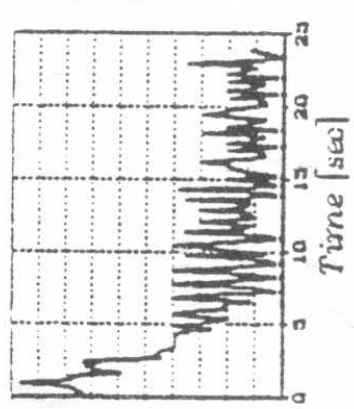

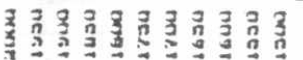

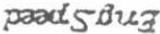

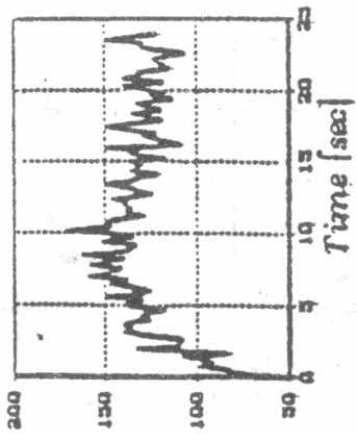

BHure :de

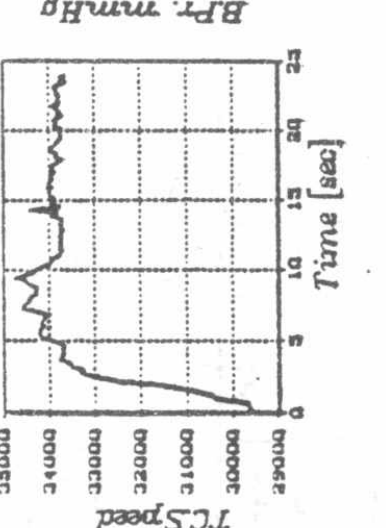

$\stackrel{2}{E}$

-

- 0

政

อ ซ

둥

는

$\equiv$

-

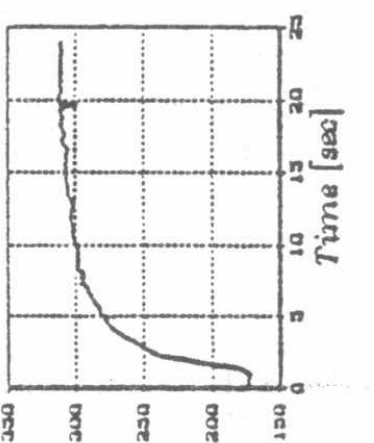

远

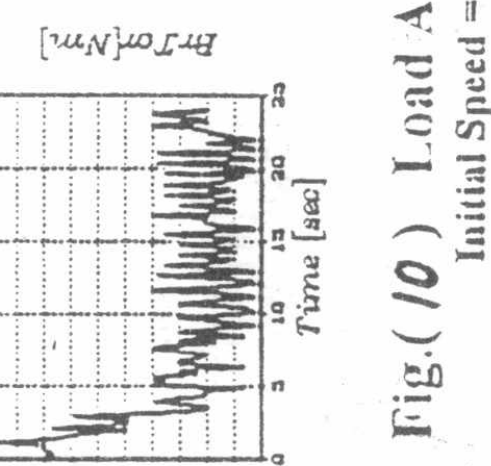

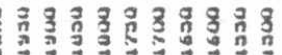

pads 1 bu

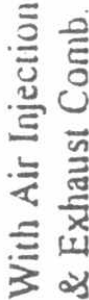




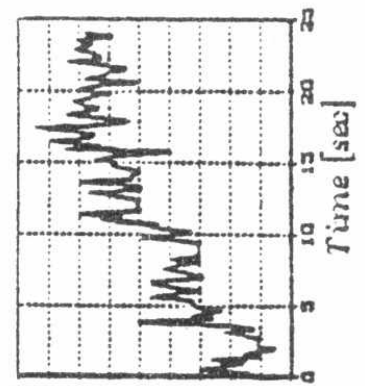

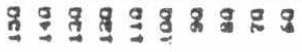

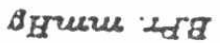

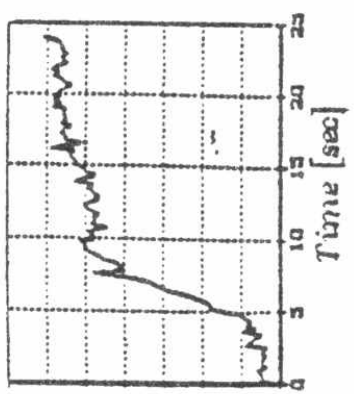

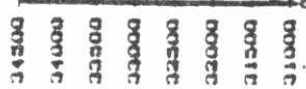

parad 5.2

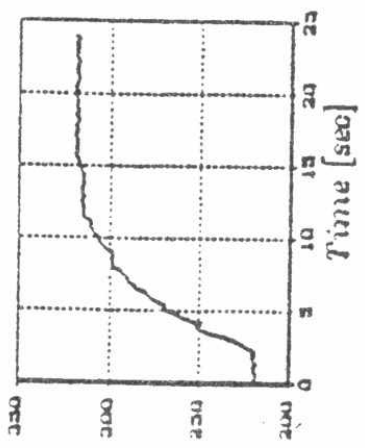

$[2 \mu N] 1052]$

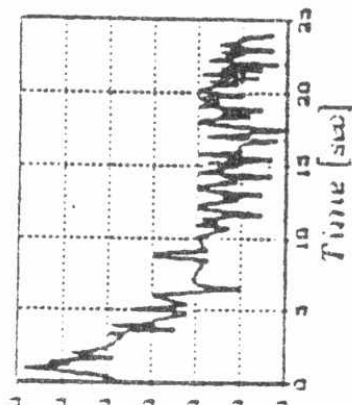

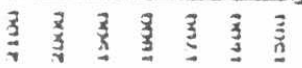

paoris duz

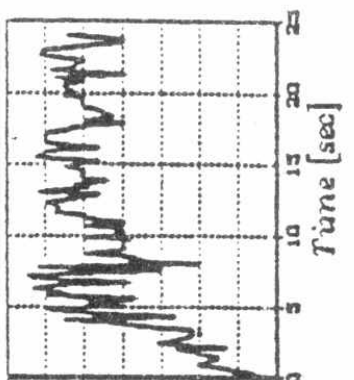

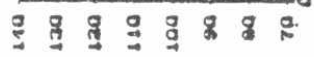

ofrures idg

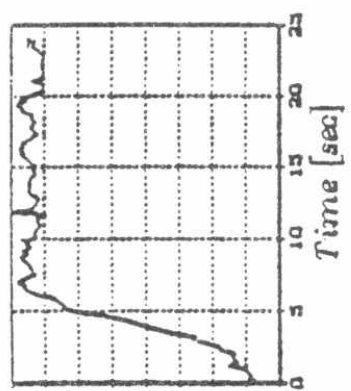

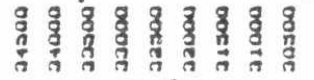

pood 5 JL

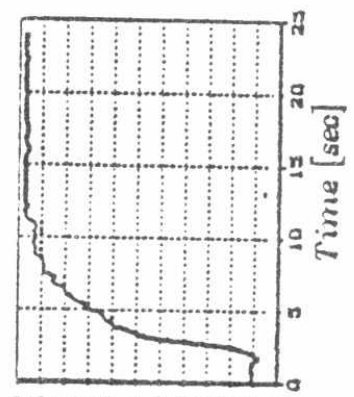

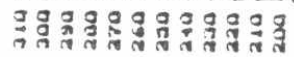
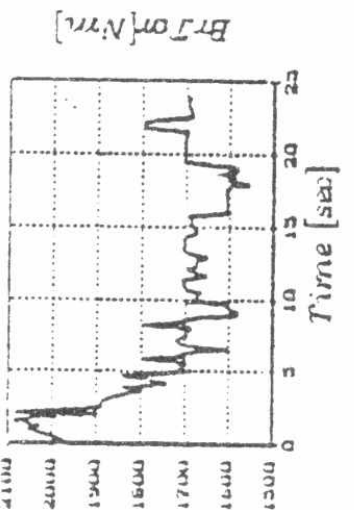

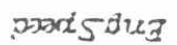

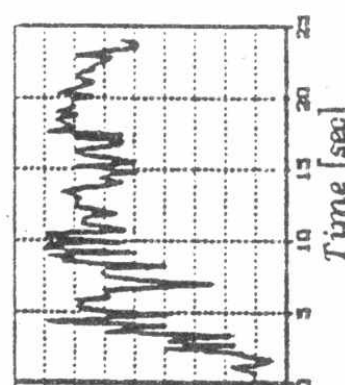

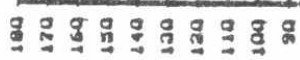

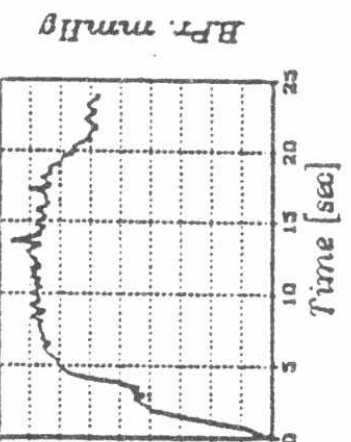

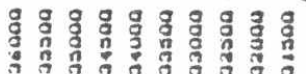
pad Sal.

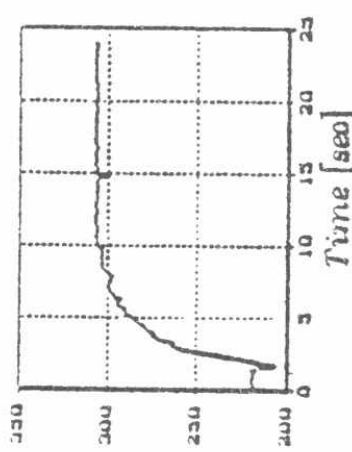

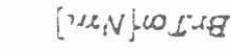

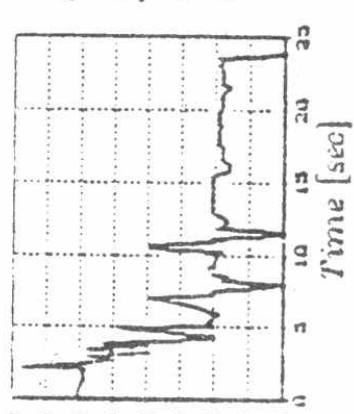

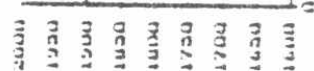

poortsilicz

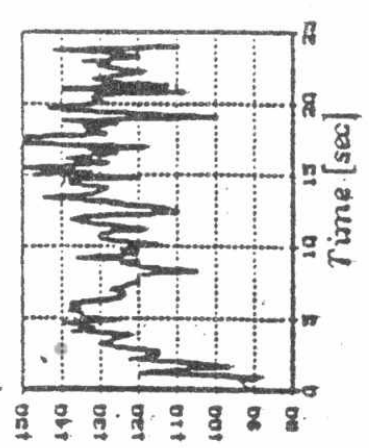

Aтrux :
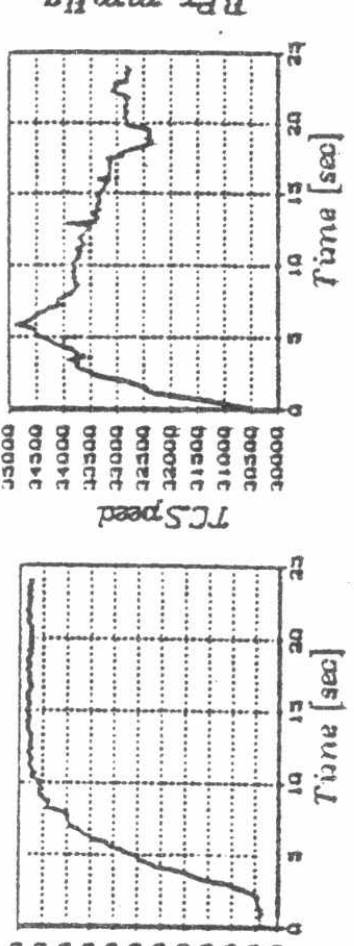

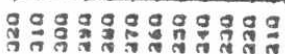

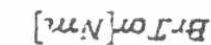

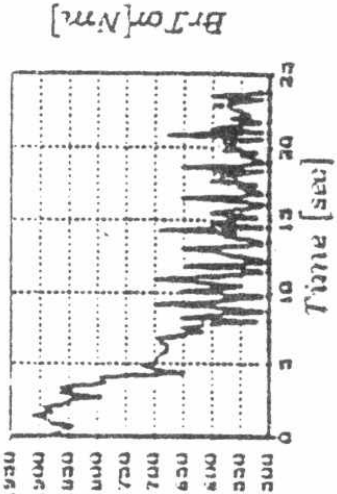

paxds soug

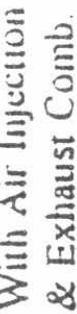

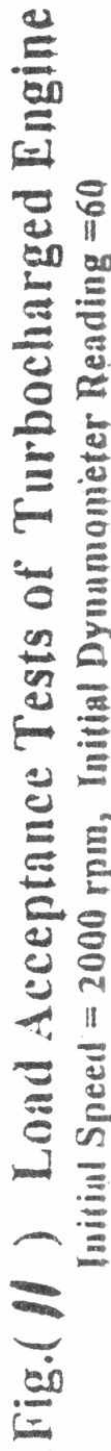

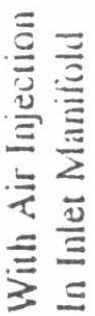

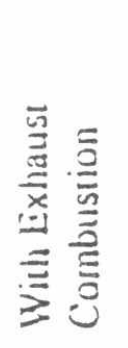

